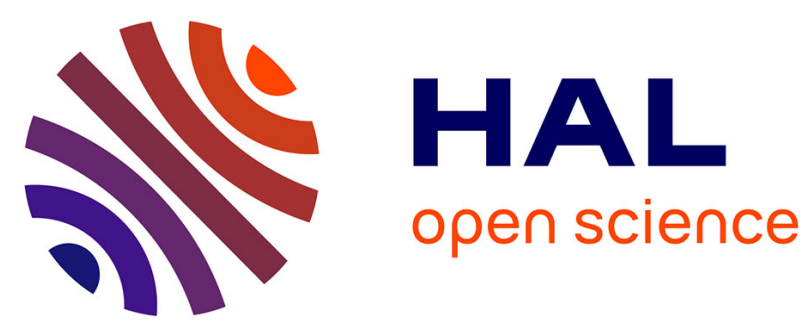

\title{
Vasorelaxing effects and inhibition of nitric oxide in macrophages by new iron-containing carbon monoxide-releasing molecules (CO-RMs).
}

Roberto Motterlini, Philip Sawle, Jehad Hammad, Brian E. Mann, Tony R. Johnson, Colin J. Green, Roberta Foresti

\section{To cite this version:}

Roberto Motterlini, Philip Sawle, Jehad Hammad, Brian E. Mann, Tony R. Johnson, et al.. Vasorelaxing effects and inhibition of nitric oxide in macrophages by new iron-containing carbon monoxide-releasing molecules (CO-RMs).. Pharmacological Research, 2013, 68 (1), pp.108-17. 10.1016/j.phrs.2012.12.001 . inserm-00796015

\section{HAL Id: inserm-00796015 https://www.hal.inserm.fr/inserm-00796015}

Submitted on 1 Mar 2013

HAL is a multi-disciplinary open access archive for the deposit and dissemination of scientific research documents, whether they are published or not. The documents may come from teaching and research institutions in France or abroad, or from public or private research centers.
L'archive ouverte pluridisciplinaire HAL, est destinée au dépôt et à la diffusion de documents scientifiques de niveau recherche, publiés ou non, émanant des établissements d'enseignement et de recherche français ou étrangers, des laboratoires publics ou privés. 


\section{Accepted Manuscript}

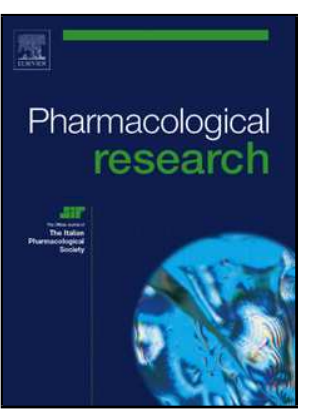

Title: Vasorelaxing Effects and Inhibition of Nitric Oxide in Macrophages by New Iron-Containing Carbon

Monoxide-Releasing Molecules (CO-RMs)

Authors: Roberto Motterlini, Philip Sawle, Jehad Hammad, Brian E. Mann, Tony R. Johnson, Colin J. Green, Roberta

Foresti

PII:

S1043-6618(12)00237-X

DOI: doi:10.1016/j.phrs.2012.12.001

Reference: YPHRS 2537

To appear in: $\quad$ Pharmacological Research

Received date: $\quad$ 16-10-2012

Revised date: 6-12-2012

Accepted date: 6-12-2012

Please cite this article as: Motterlini R, Sawle P, Hammad J, Mann BE, Johnson TR, Green CJ, Foresti R, Vasorelaxing Effects and Inhibition of Nitric Oxide in Macrophages by New Iron-Containing Carbon Monoxide-Releasing Molecules (CORMs), Pharmacological Research (2010), doi:10.1016/j.phrs.2012.12.001

This is a PDF file of an unedited manuscript that has been accepted for publication. As a service to our customers we are providing this early version of the manuscript. The manuscript will undergo copyediting, typesetting, and review of the resulting proof before it is published in its final form. Please note that during the production process errors may be discovered which could affect the content, and all legal disclaimers that apply to the journal pertain. 


\title{
Vasorelaxing Effects and Inhibition of Nitric Oxide in Macrophages
}

\section{by New Iron-Containing Carbon Monoxide-Releasing Molecules}

\section{(CO-RMs)}

\author{
Roberto Motterlini ${ }^{1}$, Philip Sawle ${ }^{2}$, Jehad Hammad ${ }^{2}$, Brian E. Mann ${ }^{3}$, Tony R. \\ Johnson $^{3}$, Colin J. Green ${ }^{2}$ and Roberta Foresti ${ }^{1}$ \\ ${ }^{I}$ INSERM U955, Equipe 3, University of Paris-Est, Faculty of Medicine, 94010 Creteil, France \\ ${ }^{2}$ Vascular Biology Unit, Department of Surgical Research, Northwick Park Institute for Medical \\ Research, Harrow, Middlesex \\ ${ }^{3}$ Department of Chemistry, University of Sheffield, Sheffield, United Kingdom
}

Corresponding authors: Roberto Motterlini or Roberta Foresti, INSERM U955, Equipe 3, Université Paris-Est, Faculté de Médecine, 94010 Creteil, France. Phone: +33-1-49813637; email: roberto.motterlini@inserm.fr; roberta.foresti@inserm.fr;

List of non-standard abbreviations: CO-RMs, carbon monoxide-releasing molecules; deoxyMb, deoxymyoglobin; DMSO, dimethylsulfoxide; HO-1, heme oxygenase-1; LPS, lipopolysaccharide; $\mathrm{MbCO}$, carbonmonoxy myoglobin; iCO-RMs, inactive CO-RMs. 


\begin{abstract}
Carbon monoxide-releasing molecules (CO-RMs) are a class of organometallo carbonyl complexes capable of delivering controlled quantities of CO gas to cells and tissues thus exerting a broad spectrum of pharmacological effects. Here we report on the chemical synthesis, CO releasing properties, cytotoxicity profile and pharmacological activities of four novel structurallyrelated iron-allyl carbonyls. The major difference among the new CO-RMs tested was that three compounds (CORM-307, CORM-308 and CORM-314) were soluble in dimethylsulfoxide (DMSO), whereas a fourth one (CORM-319) was rendered water-soluble by reacting the ironcarbonyl with hydrogen tetrafluoroborate. We found that despite the fact all compounds liberated $\mathrm{CO}, \mathrm{CO}-\mathrm{RMs}$ soluble in DMSO caused a more pronounced toxic effect both in vascular and inflammatory cells as well as in isolated vessels. More specifically, iron carbonyls soluble in DMSO released CO with a fast kinetic and displayed a marked cytotoxic effect in smooth muscle cells and RAW 247.6 macrophages despite exerting a rapid and pronounced vasorelaxation exvivo. In contrast, CORM-319 that is soluble in water and liberated $\mathrm{CO}$ with a slower rate, preserved smooth muscle cell viability, relaxed aortic tissue and exerted a significant antiinflammatory effect in macrophages challenged with endotoxin. These data suggest that iron carbonyls can be used as scaffolds for the design and synthesis of pharmacologically active CORMs and indicate that increasing water solubility and controlling the rate of $\mathrm{CO}$ release are important parameters for limiting their potential toxic effects.
\end{abstract}

Key words: carbon monoxide, vasorelaxation, inflammation, carbon monoxide-releasing molecules (CO-RMs), macrophages. 


\section{Introduction}

Carbon monoxide (CO) produced in mammals by constitutive (HO-2) and inducible (HO1) heme oxygenase enzymes is a ubiquitous signaling molecule playing a central role in the restoration of cellular homeostasis during vascular, inflammatory and metabolic disorders [1]. Endogenous CO modulates blood vessel tone [2], differentially affects the proliferation of various cells [3,4], mitigates inflammation [2] and exerts beneficial effects against a variety of pathophysiological processes that alter the function of organs and tissues [2]. The multifactorial activities of this gas dovetail with the innate cytoprotective actions of HO-1, a redox-sensitive inducible protein that responds and adapts to conditions of intense oxidative and nitrosative stress $[2,5,6]$. The essential contribution of endogenous $\mathrm{CO}$ in the regulation of cellular processes is best typified in HO-1 deficient organisms as both mice and humans lacking this enzyme die prematurely due to a high susceptibility to oxidative stress, impaired vascular function, hematologic derangements and the ensuing multiorgan failure [7,8]. From a pharmacological viewpoint, compelling results demonstrating the feasibility of mimicking the protective action of the HO-1/CO pathway have been obtained by administering $\mathrm{CO}$ gas in vivo [2]. Indeed, brief exposure of mice and rats to $\mathrm{CO}$ gas at doses that do not compromise oxygen transport to tissues results in remarkable beneficial effects against graft rejection and vascular injury [9], pulmonary hypertension [10], ischemia-reperfusion damage [11] and a wide array of disorders characterized by a strong inflammatory component [2]. Notably, the identification and development of COreleasing molecules (CO-RMs), a class of compounds that liberate $\mathrm{CO}$, clearly opened a concrete opportunity to exploit this small molecular gas for pharmacological applications [12]. 
The discovery that transition metal carbonyls function as CO-RMs in a number of in vitro, ex vivo and in vivo models confirmed the notion that delivery of $\mathrm{CO}$ is attainable by storing this gas in a stable chemical form (carbonyl complex), which can then supply $\mathrm{CO}$ to cells or tissues in a more controllable fashion [13]. Carbonyl complexes containing manganese (CORM1) and ruthenium (CORM-2) were the first compounds identified for this purpose and, despite their limited solubility in water (i.e. CORM-1 and CORM-2 are fully soluble in dimethylsulfoxide), they showed promising CO-dependent pharmacological effects including vessel relaxation in vitro and inhibition of acute hypertension in vivo [13]. Our group then developed the first prototypic water-soluble CO-releasing metal carbonyl (tricarbonylchloro(glycinato)ruthenium(II) or CORM-3) which proved to be very stable in aqueous solutions but rapidly liberated $\mathrm{CO}$ in contact with biological components or in the presence of a prototypic acceptor such as myoglobin [14]. To date CORM-3 is the best characterized and most widely used metal carbonyl as we and others demonstrated the potential of using this compound therapeutically for the treatment of disorders such as cardiac and renal ischemic injury [14,15], lethal sepsis [16], post-operative ileus [17], rheumatoid arthritis [18] hemorrhagic stroke [19], platelet aggregation, vascular thrombosis and vascular inflammation [20-22]. In recent years, different classes of CO-RMs containing a variety of transition metals such as rhenium, iron, manganese, cobalt and tungsten have been synthesized [23-28]. Although these compounds possess the ability to release $\mathrm{CO}$ in solution either spontaneously, by photodissociation or enzymatic reactions, a comparative analysis of their bioactive and pharmacological effects in relation to their solubility properties and cytotoxic profile has not been carried out. Our group has recently focused on the synthesis of CO-RMs containing either iron or manganese based on the rationale that these two metals, unlike the ruthenium found in CORM-2 
and CORM-3, are naturally present in biological systems and could therefore render COreleasing compounds more biologically compatible [29-32]. Here we studied the effects of newly synthesized CO-RMs containing an iron-allyl moiety by specifically analyzing the CO releasing properties in relation to their biochemical, biological and pharmacological parameters including solubility, cytotoxicity profile as well as vasodilatory and anti-inflammatory activities in vitro. 


\section{Materials and Methods}

\subsection{Synthesis of CORM-307 $\left(\left[\mathrm{Fe}(\mathrm{CO})_{3} I\left(\eta^{3}-\mathrm{C}_{3} \mathrm{H}_{5}\right)\right]\right)$}

This compound was prepared using a method previously described [33]. Briefly, a mixture of allyl iodide $(6.65 \mathrm{~g})$ and $\mathrm{Fe}(\mathrm{CO})_{5}(6.0 \mathrm{~g})$ was stirred for $40 \mathrm{~h}$ at $45^{\circ} \mathrm{C}$ in an air atmosphere. The mixture was then evaporated to dryness, and the residue extracted with hexane. The hexane was cooled to $-78^{\circ} \mathrm{C}$ and the precipitate collected. This procedure was repeated until washings were colorless, yielding a red-brown crystalline solid $(6.2 \mathrm{~g}, 60 \%$ yield).

\subsection{Synthesis of CORM-308 $\left(\left[\mathrm{Fe}(\mathrm{CO})_{3} \mathrm{Br}\left(\eta^{3}-\mathrm{C}_{3} \mathrm{H}_{5}\right)\right]\right)$}

This compound was prepared using a method previously described [34]. Briefly, a mixture of 1bromoprop-2-ene $(3.03 \mathrm{~g})$ and $\mathrm{Fe}_{2}(\mathrm{CO})_{9}(9.1 \mathrm{~g})$ in hexane $(20 \mathrm{ml})$ was stirred for $2 \mathrm{~h}$ at $40{ }^{\circ} \mathrm{C}$ in an air atmosphere. After filtration, the dark red solution was then concentrated and placed in the freezer. The yellow-brown solid was collected. The procedure was repeated with the mother liquor to provide a second crop of product. The crystalline product was then re-crystallized from pentane to afford a yellow-brown product $(2.4 \mathrm{~g}, 37 \%$ yield $)$.

\subsection{Synthesis of CORM-314 $\left(\left[\mathrm{Fe}(\mathrm{CO})_{3} \mathrm{Cl}\left(\eta^{3}-\mathrm{C}_{3} \mathrm{H}_{5}\right)\right]\right)$}

This compound was prepared using a method previously described [34]. Briefly, a mixture of allyl chloride $(1.91 \mathrm{~g})$ and $\mathrm{Fe}_{2}(\mathrm{CO})_{9}(9.1 \mathrm{~g})$ in hexane $(20 \mathrm{ml})$ was stirred for $2 \mathrm{~h}$ at $40^{\circ} \mathrm{C}$ in an air atmosphere. After filtration, the dark red solution was then concentrated, then exposed to air for a few minutes and placed in the freezer. The yellow solid was collected. The procedure was 
repeated with the mother liquor to provide a second crop of product. The crystalline product was then re-crystallized from pentane to afford a yellow product (1.1 g, $20 \%$ yield).

\subsection{Synthesis of CORM-319 ([Fe $\left.\left.(\mathrm{CO})_{4}\left(\eta^{3}-\mathrm{C}_{3} \mathrm{H}_{4} \mathrm{Me}\right)\right] \mathrm{BF}_{4}\right)$}

This compound was prepared using a method previously described $[35,36]$. Briefly, in a Schlenk tube, $\mathrm{Fe}_{2}(\mathrm{CO})_{9}(0.91 \mathrm{~g})$ was placed with a stirrer bar and a dropping funnel attached. The flask was filled with a CO atmosphere, before a solution of 3-buten-2-ol $(0.18 \mathrm{~g})$ in diethylether (25 ml) was added dropwise with stirring. The solution was allowed to stir overnight. The next morning the yellow solution was syringed into another Schlenk tube to remove it from precipitate. In a conical flask a solution of $\mathrm{HBF}_{4}(48 \%$ aqueous solution, $0.90 \mathrm{~g})$ in acetic anhydride $(7 \mathrm{ml})$ was prepared at $0{ }^{\circ} \mathrm{C}$. This solution was then added to the reaction mixture resulting in an immediate precipitation of a cream solid, which was collected by filtration and dried under high vacuum $(0.45 \mathrm{~g}, 58 \%$ yield $)$.

\subsection{Reagents and preparation of solutions}

Stock solutions of CORM-307, 308 and 314 (in DMSO) as well as CORM-319 (in distilled water) were prepared freshly on the day of the experiments and used within 1 min of preparation. Solutions of the inactive forms of each compound (iCO-RMs), which do not release $\mathrm{CO}$ and were used as negative controls, were also prepared. For this purpose, CORM-319 was depleted of CO by adding the compound to the cell culture medium (see below) and leaving it for at least $24 \mathrm{~h}$ at room temperature in a $5 \% \mathrm{CO}_{2}$ humidified atmosphere. The additional inactive $\mathrm{CO}-\mathrm{RMs}$ were prepared in DMSO and left for at least $48 \mathrm{~h}$ to decompose. The iCO-RMs solutions were finally bubbled with a stream of nitrogen to remove the residual $\mathrm{CO}$ present in the solution. 
Lipopolysaccharide (LPS - E. Coli serotype 026:B6) was obtained from Sigma. All other chemicals were reagent grade and obtained from Sigma unless otherwise stated.

\subsection{Cell culture}

Rat aortic smooth muscle cells (A7r5) and murine RAW264.7 monocyte macrophages were purchased from the European Collection of Cell Cultures (ECACC, Salisbury, Wiltshire, UK) and cultured in Dulbecco's modified Eagle's medium (DMEM) supplemented with 10\% fetal bovine serum, $2 \mathrm{mM}$ L-glutamine, 100 units $/ \mathrm{ml}$ penicillin and $0.1 \mathrm{mg} / \mathrm{ml}$ streptomycin. Cultures were maintained at $37^{\circ} \mathrm{C}$ in a $5 \% \mathrm{CO}_{2}$ humidified atmosphere and experiments were conducted on cells at approximately $80-90 \%$ confluence as previously described [13,37].

\subsection{Determination of $\mathrm{CO}$ release using the myoglobin assay}

The release of $\mathrm{CO}$ from iron-containing CO-RMs was assessed spectrophotometrically by measuring the conversion of deoxymyoglobin (deoxy-Mb) to carbonmonoxy myoglobin ( $\mathrm{MbCO}$ ) as previously reported $[13,14,38-40]$. A small aliquot of a stock CO-RM solution (to give a final concentration of CO-RM: 10,20 and $40 \mu \mathrm{M}$ ) was added to $1 \mathrm{ml}$ deoxy-Mb solution (final concentration of $\mathrm{Mb}$ : $53 \mu \mathrm{M}$ ) in phosphate buffer and changes in the Mb spectra were recorded over time. The amount of $\mathrm{MbCO}$ formed was quantified by measuring the absorbance at $540 \mathrm{~nm}$ (extinction coefficient $=15.4 \mathrm{M}^{-1} \mathrm{~cm}^{-1}$ ) and plotted over time.

\subsection{Detection of $\mathrm{CO}$ release from CO-RMs using an amperometric CO sensor}

The spontaneous release of $\mathrm{CO}$ from the selected CO-RMs was measured using a CO-sensitive electrode (World Precision Instrument, Stevenage, Herts, UK). Technical details of this electrode have been reported previously by our group [41,42]. The electrode was immersed into distilled 
water containing $0.1 \mathrm{M}$ phosphate buffer $(\mathrm{pH}=7.4)$ and equilibrated for $30 \mathrm{~min}$ prior to addition of CO-RMs $(100 \mu \mathrm{M})$ and changes in current were continuously recorded over time. The experiments were conducted at $37^{\circ} \mathrm{C}$ and the solutions were maintained at the desired temperature using a Grant W6 thermostat (Cambridge).

\subsection{Cell viability assays}

Cell viability was determined in macrophages and aortic smooth muscle cells using an Alamar Blue assay kit and LDH kit and carried out according to the manufacturer's instructions (Serotec, UK) as previously reported by us [43]. The alamar blue assay is based on the detection of metabolic activity of living cells using a redox indicator which changes from an oxidised (blue) form to a reduced (red) form. The intensity of the red colour is proportional to the metabolism of the cells, which is calculated as the difference in absorbance between $570 \mathrm{~nm}$ and $600 \mathrm{~nm}$ and expressed as a percentage of control. Lactate dehydrogenase (LDH) released in the medium was also measured and used as an index of cellular damage. Since the data on LDH release were very similar to the ones obtained with the Alamar Blue assay, only results based on the second method are presented.

\subsection{Nitrite assay}

Macrophages were exposed for $24 \mathrm{hr}$ to LPS $(1 \mu \mathrm{g} / \mathrm{ml})$ in the presence or absence of CO-RMs $(10,50$ and $100 \mu \mathrm{M})$ and nitrite levels were determined at the end of the incubation. Experiments were also conducted in the presence of negative controls (iCO-RMs) to verify whether the effects observed were only due to CO liberated by CO-RMs or caused by other parts of the molecules. After incubation, nitrite levels were determined using the Griess method as previously described 
[37,44]. This measurement is an indication of $\mathrm{NO}$ production following stimulation of inducible nitric oxide synthase (iNOS). Briefly, the medium from treated cells cultured in 24 well plates was removed and placed into a 96 well plate (50 $\mu 1$ per well). The Griess reagent was added to each well to begin the reaction, the plate was shaken for $10 \mathrm{~min}$ and the absorbance read at 550 $\mathrm{nm}$ on a Molecular Devices VERSAmax plate reader. The nitrite level in each sample was calculated from a standard curve generated with sodium nitrite $(0 \mu \mathrm{M}$ to $300 \mu \mathrm{M}$ in cell culture medium).

\subsection{Aortic ring preparation}

Transverse ring sections were prepared from thoracic aortas of male adult Sprague Dawley rats (350 g) as previously described $[45,46]$. After removal of superficial fat and connective tissue, the aorta was cut into rings and mounted in organ baths containing normal Krebs-Henseleit solution with the following composition (mM): $\left(\mathrm{NaCl} 118, \mathrm{KCl} 4.7, \mathrm{KH}_{2} \mathrm{PO}_{4} 1.2, \mathrm{MgSO}_{4} .7 \mathrm{H}_{2} \mathrm{O}\right.$ $1.2, \mathrm{NaHCO}_{3} 22$, glucose $11, \mathrm{~K}^{+}$EDTA $\left.0.03, \mathrm{CaCl}_{2} 2.5\right)$. The bath solution was maintained at 37 ${ }^{\circ} \mathrm{C}$ and bubbled continuously with a mixture of $95 \% \mathrm{O}_{2}$ and $5 \% \mathrm{CO}_{2}$. Aortic rings were equilibrated for $30 \mathrm{~min}$ at a resting tension of $2 \mathrm{~g}$ and pre-contracted with $\mathrm{KCl}(100 \mathrm{mM})$ before specific experimental protocols were initiated. Responses were recorded isometrically via a force- transducer connected to a Power Lab recording system (AD Instruments, UK). The extent of vasorelaxation over time elicited by a single addition of CO-RMs $(100 \mu \mathrm{M})$ was assessed in aortic rings pre-contracted with phenylephrine $(1 \mu \mathrm{M})$ and compared with the effect produced by the inactive forms (iCO-RMs). Vasorelaxation was expressed as a reduction (in percentage) of the initial contraction produced by phenylephrine. 


\subsection{Statistical Analysis}

Statistical analysis was performed using one-way ANOVA combined with Bonferroni test.

Differences were considered to be significant at $P<0.05$. 


\section{Results}

\subsection{Detection of $\mathrm{CO}$ release from iron-containing $\mathrm{CO}-\mathrm{RMS}$}

The chemical structures of CORM-307, CORM-308, CORM-314 and CORM-319 are represented in Figure 1A. While CORM-307, 308 and 314 represent examples of an isostructural series of iron carbonyl complexes of the general formula $\left[\mathrm{Fe}(\right.$ allyl $\left.) \mathrm{X}(\mathrm{CO})_{3}\right]$ with the halide ligand $\mathrm{X}=\mathrm{Cl}, \mathrm{Br}$, or I and a facial arrangement of the three CO ligands, CORM-319 is distinct from these by the presence of a fourth carbonyl ligand instead of the halide, which leads to a trans OCFe-CO orientation of two of the carbonyl groups. The halide-containing compounds are soluble in DMSO, while CORM-319 is soluble in water. We tested the ability of these metal carbonyl complexes to release $\mathrm{CO}$ by measuring the conversion of deoxy- $\mathrm{Mb}$ to $\mathrm{MbCO}$ over time $[13,14,38,41]$. We report in Figure 1B the maximal MbCO value reached for each CO-RM at three different concentrations. As shown all CO-RMs (10, 20 and $40 \mu \mathrm{M})$ liberated $\mathrm{CO}$ in a concentration-dependent manner. The amount of $\mathrm{MbCO}$ formed suggests that approximately one mole of $\mathrm{CO}$ is released per mole of compound at all concentrations used.

\subsection{Time-course of $\mathrm{CO}$ release and vascular activities of iron-containing $C O-R M s$}

The conversion of deoxy-Mb to $\mathrm{MbCO}$ can be followed over time and the amount of $\mathrm{MbCO}$ quantified by measuring the changes in the absorption spectra of this protein. As shown in Figure 2A, addition of $40 \mu \mathrm{M}$ CORM-307 to a Mb solution rapidly changes the deoxy-Mb spectrum into spectra typical of $\mathrm{MbCO} . \mathrm{Mb}$ appears to be fully saturated with $\mathrm{CO}$ within 5 min as all the spectra recorded at subsequent times overlap to this initial spectrum. The quantification of $\mathrm{MbCO}$ over time is reported in Figure 2B and shows that the inactive compound (iCORM-307) released 
significantly much less $\mathrm{CO}$ compared to the active one. The vasoactive properties of CORM-307 were evaluated using the isolated aortic ring preparation and the data are shown in Figure 2C. Addition of $100 \mu \mathrm{M}$ CORM-307 produced a profound vasorelaxation over time and a similar result was obtained with the inactive compound (iCORM-307). The vasorelaxation mediated by both CORM-307 and iCORM-307 was gradual and progressive reaching a maximum at $60 \mathrm{~min}$ after addition of the compounds to the organ bath. These data suggest that the vasodilatation mediated by CORM-307 cannot be ascribed solely to the liberated $\mathrm{CO}$ as the CO-depleted compound itself can partially contribute to the observed effect. It is important to note that CORM-307 caused a sustained and progressive vasodilatation over time with no re-contraction of the vessel after the treatment. This suggests that ensuing tissue damage may have occurred and we examined this possibility by assessing the viability of rat smooth muscle cells incubated for $24 \mathrm{~h}$ with increasing concentrations of CORM-307. As shown in Figure 2D, concentrations of CORM-307 as low as $10 \mu \mathrm{M}$ caused a complete loss in cell viability. The inactive compound, although less toxic, also significantly decreased cell viability (44\%) at $100 \mu \mathrm{M}$. Although with some quantitative differences (see Figures 3 and 4), similar profiles on the rate of $\mathrm{CO}$ release, vasodilatation and viability of smooth muscle cells were obtained with CORM-308 (Figures 3A, 3B, 3C and 3D) and CORM-314 (Figures 4A, 4B, 4C and 4D). However, iCORM-308 and iCORM-314 exerted less vasodilatation compared to their active counterparts. In general, the iron-carbonyl complexes soluble in DMSO (CORM-307, COMR-308 and CORM-314) are good and fast releasers but possess a certain degree of toxicity which can be revealed both in vascular tissue and smooth muscle cells in culture. Interestingly, a rather different profile was observed with CORM-319, a water-soluble iron-containing CORM. As shown in Figures 5A and 5B, CORM-319 released CO to myoglobin with a slower rate compared to the other CO-RMs. The 
experiment using the $\mathrm{CO}$ electrode reveals that CORM-319 releases some CO spontaneously in buffer solution (see inset in Figure 5B). The CO spontaneously released with this method is hard to quantify but from the curve fitted to the spectral $\mathrm{MbCO}$ data we calculate that the half-life of CORM-319 is around 18 min. Predictably, the inactive compound (iCORM-319) did not release any detectable $\mathrm{CO}$ to $\mathrm{Mb}$ (Figure 5B). The water-soluble CORM-319 caused a rapid and concentration-dependent vasorelaxation in pre-contracted isolated aortic rings. In fact, as shown in Figure 5C, the vasodilatation reached a maximum 10 min after addition of CORM-319; this was quantified as $21.4 \pm 6.1 \%$ at $12.5 \mu \mathrm{M}, 39.1 \pm 7.7 \%$ at $50 \mu \mathrm{M}$ and $57.1 \pm 2.7 \%$ at $100 \mu \mathrm{M}$ CORM-319. Since $100 \mu \mathrm{M}$ iCORM-319 produced only a slight and significantly less relaxation $(6.8 \pm 3.2 \%, \mathrm{p}<0.05)$, the data strongly suggest that $\mathrm{CO}$ liberated from this iron-carbonyl complex is responsible for the observed effect. In addition, the fact that the vessels promptly re-contracted after the maximal relaxation was achieved is indicative of a much less toxic effect on the vascular tissue compared to the DMSO-soluble compounds tested. This is supported by the data shown in Figure 5D showing that rat smooth muscle cells incubated for $24 \mathrm{~h}$ with increasing concentrations of CORM-319 $(10,50$ and $100 \mu \mathrm{M})$ are significantly more viable than cells treated with CORM307 (see Figure 2D), CORM-308 (see Figure 3D) or CORM-314 (see Figure 4D).

\subsection{Effect of iron-containing CO-RMs on cell viability and LPS-mediated nitrite production in} macrophages

As shown in Figure 6, iron-containing CO-RMs affected the viability of macrophages followed a profile similar to that obtained with smooth muscle cells, CORM-319 being significantly less toxic than the DMSO-soluble compounds. Specifically, the calculated $\mathrm{IC}_{50}$ (the concentration at which $50 \%$ of the cells are not viable) was $9.1 \mu \mathrm{M}$ for CORM-307 (Figure $6 \mathrm{~A}$ ), $11.9 \mu \mathrm{M}$ for 
CORM-308 (Figure 6B), $23.6 \mu \mathrm{M}$ for CORM-314 (Figure 6C) and $797 \mu \mathrm{M}$ for CORM-319 (Figure 6D). Therefore, the water-soluble CORM-319 appears to be approximately 40 times less toxic than iron-containing carbonyls that are not soluble in water. Since CORM-319 was the most promising iron-contiaing compound tested, we investigated its potential anti-inflammatory activity. We have previously reported on the biological properties of CORM-2 and CORM-3, two carbonyl complexes containing ruthenium as transition metal, and their ability to significantly reduce both TNF- $\alpha$ and nitrite production in macrophages stimulated with LPS [37]. As shown in Figure 7, CORM-319 significantly attenuated LPS-induced nitrite production in a concentrationdependent manner. This effect appeared to be dependent on the CO released by the compounds since the inactive form (iCORM-319) did not have any effect on nitrite levels. It is important to note that the concentrations which showed an effective reduction in LPS-mediated nitrite production $(10,50$ and $100 \mu \mathrm{M})$ did not cause any toxic effect in macrophages (see Figure 6D). 


\section{Discussion}

The emerging evidence that $\mathrm{CO}$ serves as signaling and cytoprotective mediator within mammalian organisms prompted scientists to develop pharmacological approaches for the therapeutic use of this gas. Transition metal carbonyls capable of liberating CO in biological systems known as CO-releasing molecules (CO-RMs) represent an alternative to $\mathrm{CO}$ gas inhalation as they can be designed to deliver $\mathrm{CO}$ in a controlled and physiological fashion $[47,48]$. The present study reports on a new class of iron carbonyl complexes that function as CO-RMs in cells and tissues revealing a differential cytotoxic as well as pharmacological profile of these compounds depending on their solubility properties and kinetic of $\mathrm{CO}$ release. Specifically, CORM-307, CORM-308 and CORM-314 that are soluble in DMSO release CO with a fast kinetic and display a marked cytotoxic effect in vascular and inflammatory cells despite exerting pronounced vasorelaxation ex-vivo. In contrast, CORM-319 that is soluble in water and liberates $\mathrm{CO}$ with a slower rate, preserves smooth muscle cell viability, relaxes aortic tissue and exerts a significant anti-inflammatory effect in endotoxin-stimulated macrophages. These data suggest that iron carbonyls can be used as scaffolds for the design and synthesis of pharmacologically active CO-RMs and indicate that increasing water solubility and controlling the rate of $\mathrm{CO}$ release are important parameters for limiting their potential toxic effects.

Different classes of transition metal-containing CO-RMs have been synthesized in the last decade following the discovery that both DMSO- (CORM-2) and water-soluble (CORM-3) ruthenium carbonyls exert a variety of CO-mediated pharmacological effects in vitro and in vivo including vasorelaxation, protection against ischemia as well as anti-apoptotic and antiinflammatory activities $[13,14,16,37,49,50]$. The majority of these compounds have been 
designed with the main objective of producing stable CO-RMs which could then be triggered to liberate $\mathrm{CO}$ by a given stimulus in solution. For instance, certain metal carbonyls are known to be light sensitive and several newly synthesized CO-RMs containing either iron or manganese have been shown to release $\mathrm{CO}$ upon irradiation with either visible or UV light $[24,25,51]$. Other metal carbonyls possess different properties since liberation of $\mathrm{CO}$ and the rate of $\mathrm{CO}$ release can be triggered by various mechanisms involving interaction with the solvent, loss or substitution of ligands present in the metal center, oxidation of the metal, the presence of a prototypic $\mathrm{CO}$ acceptor in the vicinity or a combination of any of these $[26,28,52,53]$. Irrespective of the amount and kinetic of $\mathrm{CO}$ release, which we are learning to be modulated by different characteristics of the CO-RM scaffold, it is evident that many other properties need to be considered for the optimization of pharmacologically active molecules. These include the choice of the metal, stability of the complex, its solubility and the degree of reactivity of the metal with intracellular components other than the target(s). These important aspects will aid the development of compounds with reduced side effects, limited toxicity and improved efficacy. Therefore, the type of screening for the identification of novel CO-RMs is not trivial and should include not only assays for the quantification of $\mathrm{CO}$ release but also appropriate in vitro and/or in vivo tests for the assessment of CO-mediated pharmacological effects coupled with their cytotoxicity profile.

Based on previous experience and through a preliminary screening of a group of iron indenyl carbonyl compounds that were tested for their CO-releasing properties, we observed that introducing water solubility significantly reduces the cytotoxic effect of CO-RMs [30]. In this study we utilized a similar class of iron complexes to assess more in detail this aspect and explore a possible correlation between the differential solubility of iron carbonyls in hydrophobic and hydrophilic solutions, their toxicity profile and CO-mediated pharmacological actions. These 
CO-RMs were selected for comparison as they are structurally related and liberate the same total amount of $\mathrm{CO}$ to myoglobin. In line with our predictions, we found that among the iron-allyl carbonyls tested, the ones soluble in DMSO (CORM-307, CORM-308 and CORM-314) caused a much more significant cytotoxic effect on cultured cells compared to the one soluble in water (CORM-319). In smooth muscle cells, treatment with DMSO-soluble CO-RMs at concentrations as low as $10 \mu \mathrm{M}$ resulted in complete loss of viability whereas $(60 \%)$ were still viable after treatment with $100 \mu \mathrm{M}$ CORM-319. In addition, in isolated aortic rings both DMSO- and watersoluble CO-RMs induced a marked vasorelaxation but with a totally different kinetic. While CORMs soluble in DMSO progressively relaxed vessels over time reaching 90\% relaxation at $1 \mathrm{~h}$ without subsequent re-contraction, the water-soluble CORM-319 elicited significant concentration-dependent relaxation followed by a rapid regain in contractility within $20 \mathrm{~min}$. The inability of dilated vessels to recontract after addition of CO-RMs soluble in DMSO is indicative of an ensuing vascular damage and may be due to the potent toxic effect caused by these compounds on smooth muscle cells. However, it should be noted that viability of smooth muscle cells was assessed $24 \mathrm{~h}$ after exposure to CO-RMs while the effect observed in vessels occurred within $1 \mathrm{~h}$ of treatment.

Thus, iron carbonyl CO-RMs soluble in DMSO promote a marked toxic effect in cells and tissues of vascular origin. The results obtained with CO-RMs depleted of CO (iCO-RMs) are rather instructive and helpful in understanding the possible causes of toxicity as they show that iCO-RMs soluble in DMSO cause far less smooth muscle cytotoxicity than their active counterparts. In the case of iCORM-308 and iCORM-314, their better cytotoxic profile is also accompanied by decreased vascular damage as indicated by maintenance of contractility following a transient vasodilatory effect elicited by these two compounds. At first, one could 
argue that $\mathrm{CO}$ is the factor responsible for the observed vascular damage as DMSO-soluble CORMs could be more toxic by releasing CO with a very rapid kinetic compared to CORM-319, which liberates $\mathrm{CO}$ at a much slower rate. However, this is unlikely since all iCO-RMs soluble in DMSO still significantly decreased cell viability within the range of $10-50 \mu \mathrm{M}$ while the watersoluble CORM-391 and iCORM-391 did not. In addition, previous results have clearly shown that at these concentrations $\mathrm{CO}$ gas is not toxic to cells or vascular tissues [54], and for many "fast' and "slow" water-soluble CO-RMs tested so far toxicity in vitro can be observed only at concentrations above $100 \mu \mathrm{M}$ [55]. The higher toxicity of the DMSO-soluble iron carbonyl complexes might be due to a more efficient cellular uptake, but this needs to be confirmed by assessing the lipophilicity or by measuring the precise amount of internalization of these compounds. It cannot be excluded a priori that the presence of iron, after liberation of $\mathrm{CO}$, would favour some Fenton reaction activities inside the cells and consequently the increased production of reactive oxygen species (ROS) could contribute to the toxic effect and the lack in regaining contractility we observed $[46,56]$. This is supported also by circumstantial evidence showing that an increased production of ROS can be detected in cells treated with ruthenium-based CORM-2, which is soluble in DMSO [57,58].

The experiments conducted on macrophages further support the idea that iron-carbonyls solubilised in DMSO are inherently more toxic. First of all, it is interesting to note that compared to smooth muscle cells, RAW264.7 are significantly more resistant to the toxic effect elicited by all iron-containing CO-RMs. In fact, while smooth muscle cells treated with $10 \mu \mathrm{M}$ DMSOsoluble CO-RMs for $24 \mathrm{~h}$ exhibited $100 \%$ loss in cell viability, more than $50 \%$ viable macrophages were observed after exposure to $10 \mu \mathrm{M}$ CORM-307, 308 or 309. Moreover, the $\mathrm{IC}_{50}$ for the water-soluble CORM-319 is markedly increased from $\approx 100 \mu \mathrm{M}$ in smooth cells to 
$797 \mu \mathrm{M}$ in macrophages. When macrophages were challenged with LPS, we found that CORM319, but not iCORM-319, inhibited nitrite production in a concentration-dependent manner demonstrating that $\mathrm{CO}$ is the major component responsible for this anti-inflammatory effect. These data confirm that within the range of concentrations 10 to $100 \mu \mathrm{M}$, both CORM-319 itself and $\mathrm{CO}$ liberated from it are clearly not toxic. Thus, compared to previously published reports, our present study reveals a marked improvement in the synthesis of iron carbonyls for pharmacological applications highlighting the importance of increasing their solubility in water in order to limit cytotoxic side effects [25,30,59]. Several newly synthesized CO-RMs based on iron metal carbonyls have been recently reported by different groups who have primarily focussed on generating compounds that can liberate $\mathrm{CO}$ in solution by exploiting the chemical reactivity of metal-CO bond towards various mechanisms of action of $\mathrm{CO}$ release $[25,27,30,32,59]$. However, and in view of the data presented here, the intrinsic toxicity of these iron-containing CO-RMs is a major obstacle to overcome; thus, efforts should be made to carefully assess the cytotoxic profile in different cell types and tissues every time a novel CO-RM is synthesized.

In conclusion, the results presented here disclose important information on the viability of water-soluble iron carbonyls as CO-RMs since we identified that vasodilatory and antiinflammatory effects are strictly related to the extent and rate of CO liberation without any contribution of the ensuing cytotoxic activity observed for similar compounds soluble in DMSO.

\section{Acknowledgments}


We would like to thank the AREMCAR Foundation for current financial support. The authors would also like to thank many colleagues at Northwick Park Institute for Medical Research (Harrow, United Kingdom) for their contribution and support. 


\section{References}

[1] Scott JR, Chin BY, Bilban MH, Otterbein LE. Restoring HOmeostasis: is heme oxygenase-1 ready for the clinic? Trends Pharmacol Sci 2007;28:200-205.

[2] Ryter SW, Alam J, Choi AM. Heme oxygenase-1/carbon monoxide: from basic science to therapeutic applications. Physiological Reviews 2006;86:583-650.

[3] Clark JE, Green CJ, Motterlini R. Involvement of the heme oxygenase-carbon monoxide pathway in keratinocyte proliferation. Biochem Biophys Res Commun 1997;241:215-220.

[4] Peyton KJ, Reyna SV, Chapman GB, Ensenat D, Liu XM, Wang H, Schafer AI, Durante W. Heme oxygenase-1-derived carbon monoxide is an autocrine inhibitor of vascular smooth muscle cell growth. Blood 2002;99:4443-4448.

[5] Motterlini R, Green CJ, Foresti R. Regulation of heme oxygenase-1 by redox signals involving nitric oxide. Antiox Redox Signal 2002;4:615-624.

[6] Vesely MJJ, Exon DJ, Clark JE, Foresti R, Green CJ, Motterlini R. Heme oxygenase-1 induction in skeletal muscle cells: hemin and sodium nitroprusside are regulators in vitro. Am J Physiol 1998;275:C1087-C1094.

[7] Poss KD and Tonegawa S. Heme oxygenase 1 is required for mammalian iron reutilization. Proc Natl Acad Sci USA 1997;94:10919-10924.

[8] Ohta K, Yachie A, Fujimoto K, Kaneda H, Wada T, Toma T, Seno A, Kasahara Y, Yokoyama H, Seki H, Koizumi S. Tubular injury as a cardinal pathologic feature in human heme oxygenase-1 deficiency. Am J Kidney Dis 2000;35:863-870.

[9] Otterbein LE, Zuckerbraun BS, Haga M, Liu F, Song R, Usheva A, Stachulak C, Bodyak N, Smith RN, Csizmadia E, Tyagi S, Akamatsu Y, Flavell RJ, Billiar TR, Tzeng E, Bach FH, Choi AM, Soares MP. Carbon monoxide suppresses arteriosclerotic lesions 
associated with chronic graft rejection and with balloon injury. Nature Med 2003;9:183190.

[10] Zuckerbraun BS, Chin BY, Wegiel B, Billiar TR, Czsimadia E, Rao J, Shimoda L, Ifedigbo E, Kanno S, Otterbein LE. Carbon monoxide reverses established pulmonary hypertension. J Exp Med 2006;203:2109-2119.

[11] Kohmoto J, Nakao A, Kaizu T, Tsung A, Ikeda A, Tomiyama K, Billiar TR, Choi AM, Murase N, McCurry KR. Low-dose carbon monoxide inhalation prevents ischemia/reperfusion injury of transplanted rat lung grafts. Surgery 2006;140:179-185.

[12] Motterlini R and Otterbein LE. The therapeutic potential of carbon monoxide. Nat Rev Drug Discov 2010;9:728-743.

[13] Motterlini R, Clark JE, Foresti R, Sarathchandra P, Mann BE, Green CJ. Carbon monoxide-releasing molecules: characterization of biochemical and vascular activities. Circ Res 2002;90:E17-E24.

[14] Clark JE, Naughton P, Shurey S, Green CJ, Johnson TR, Mann BE, Foresti R, Motterlini R. Cardioprotective actions by a water-soluble carbon monoxide-releasing molecule. Circ Res 2003;93:e2-e8.

[15] Varadi J, Lekli I, Juhasz B, Bacskay I, Szabo G, Gesztelyi R, Szendrei L, Varga E, Bak I, Foresti R, Motterlini R, Tosaki A. Beneficial effects of carbon monoxide-releasing molecules on post-ischemic myocardial recovery. Life Sci 2007;80:1619-1626.

[16] Lancel S, Hassoun SM, Favory R, Decoster B, Motterlini R, Neviere R. Carbon monoxide rescues mice from lethal sepsis by supporting mitochondrial energetic metabolism and activating mitochondrial biogenesis. J Pharmacol Exp Ther 2009;1329:641-648.

[17] De Backer O, Elinck E, Blanckaert B, Leybaert L, Motterlini R, Lefebvre RA. Watersoluble CO-releasing molecules (CO-RMs) reduce the development of postoperative ileus via modulation of MAPK/HO-1 signaling and reduction of oxidative stress. Gut 2009;58:347-356. 
[18] Maicas N, Ferrandiz ML, Devesa I, Motterlini R, Koenders MI, van den Berg WB, Alcaraz MJ. The CO-releasing molecule CORM-3 protects against articular degradation in the K/BxN serum transfer arthritis model. Eur J Pharmacol 2010;634:184-191.

[19] Yabluchanskiy A, Sawle P, Homer-Vanniasinkam S, Green CJ, Foresti R, Motterlini R. CORM-3, a carbon monoxide-releasing molecule, alters the inflammatory response and reduces brain damage in a rat model of hemorrhagic stroke. Crit Care Med 2012;40:544552.

[20] Chlopicki S, Olszanecki R, Marcinkiewicz E, Lomnicka M, Motterlini R. Carbon monoxide released by CORM-3 inhibits human platelets by a mechanism independent of soluble guanylate cyclase. Cardiovasc Res 2006;71:393-401.

[21] Kramkowski K, Leszczynska A, Mogielnicki A, Chlopicki S, Fedorowicz A, Grochal E, Mann B, Brzoska T, Urano T, Motterlini R, Buczko W. Antithrombotic Properties of Water-Soluble Carbon Monoxide-Releasing Molecules. Arterioscler Thromb Vasc Biol 2012;32:2149-2157.

[22] Urquhart P, Rosignoli G, Cooper D, Motterlini R, Perretti M. Carbon monoxide-releasing molecules modulate leukocyte-endothelial interactions under flow. J Pharmacol Exp Ther 2007;321:656-662.

[23] Zobi F, Degonda A, Schaub MC, Bogdanova AY. CO releasing properties and cytoprotective effect of cis-trans-[Re(II)(CO)2Br2L2]n complexes. Inorg Chem 2010;49:7313-7322.

[24] Niesel J, Pinto A, Peindy N'dongo HW, Merz K, Ott I, Gust R, Schatzschneider U. Photoinduced CO release, cellular uptake and cytotoxicity of a tris(pyrazolyl)methane (tpm) manganese tricarbonyl complex. Chem Commun 2008;15:1798-1800.

[25] Kretschmer R, Gessner G, Gorls H, Heinemann SH, Westerhausen M. Dicarbonylbis(cysteamine)iron(II): a light induced carbon monoxide releasing molecule based on iron (CORM-S1). J Inorg Biochem 2011;105:6-9. 
[26] Atkin AJ, Williams S, Sawle P, Motterlini R, Lynam JM, Fairlamb IJ. mu(2)-Alkyne dicobalt(0)hexacarbonyl complexes as carbon monoxide-releasing molecules (CO-RMs): probing the release mechanism. Dalton Trans 2009;19:3653-3656.

[27] Romanski S, Kraus B, Schatzschneider U, Neudorfl JM, Amslinger S, Schmalz HG. Acyloxybutadiene iron tricarbonyl complexes as enzyme-triggered CO-releasing molecules (ET-CORMs). Angew Chem Int Ed Engl 2011;50:2392-2396.

[28] Rimmer RD, Richter H, Ford PC. A photochemical precursor for carbon monoxide release in aerated aqueous media. Inorg Chem 2010;49:1180-1185.

[29] Sawle P, Hammad J, Fairlamb IJ, Moulton B, O'Brien CT, Lynam JM, Duhme-Klair AK, Foresti R, Motterlini R. Bioactive properties of iron-containing carbon monoxidereleasing molecules (CO-RMs). J Pharmacol Exp Ther 2006;318:403-410.

[30] Hewison L, Crook SH, Johnson TR, Mann BE, Adams H, Plant SE, Sawle P, Motterlini R. Iron indenyl carbonyl compounds: CO-releasing molecules. Dalton Trans 2010;39:8967-8975.

[31] Crook SH, Mann BE, Meijer JAHM, Adams H, Sawle P, Scapens D, Motterlini R. $[\mathrm{Mn}(\mathrm{CO}) 4\{\mathrm{~S} 2 \mathrm{CNMe}(\mathrm{CH} 2 \mathrm{CO} 2 \mathrm{H})\}]$, a new water-soluble CO-releasing molecule. Dalton Trans 2011;40:4230-4235.

[32] Hewison L, Johnson TR, Mann BE, Meijer AJ, Sawle P, Motterlini R. A re-investigation of [Fe(1-cysteinate)(2)(CO)(2)](2-): an example of non-heme $\mathrm{CO}$ coordination of possible relevance to CO binding to ion channel receptors. Dalton Trans 2011;40:8328-8334.

[33] Nesmeyanov AA and Kritsakaya II. Some views on the structure and chemistry of $\pi$-allyl complexes. J Organomet Chem 1968;14:387-394.

[34] Murdoch HD and Weiss E. $\pi$-Allyl-eisencarbonyl-halogenide. Helv Chim Acta 2004;45:1927-1933.

[35] Dieter J and Nicholas KM. A convenient stereoselective synthesis of cationic ( $\eta^{3}$-allyl) iron tetracarbonyl complexes. J Organomet Chem 1981;212:107-113. 
[36] Enders D, Jandeleit B, von Berg S, Raabe G, Runsink J. Iron-mediated allylic substitution reactions with chirality transfer. Stereochemistry of the formation of diastereo- and enantiomerically enriched olefinic and allylic tetracarbonyl iron complexes. Organometallics 2001;20:4312-4332.

[37] Sawle P, Foresti R, Mann BE, Johnson TR, Green CJ, Motterlini R. Carbon monoxidereleasing molecules (CO-RMs) attenuate the inflammatory response elicited by lipopolysaccharide in RAW264.7 murine macrophages. Br J Pharmacol 2005;145:800810.

[38] Motterlini R, Mann BE, Johnson TR, Clark JE, Foresti R, Green CJ. Bioactivity and pharmacological actions of carbon monoxide-releasing molecules. Curr Pharmacol Design 2003;9:2525-2539.

[39] Atkin AJ, Lynam JM, Moulton BE, Sawle P, Motterlini R, Boyle NM, Pryce MT, Fairlamb IJ. Modification of the deoxy-myoglobin/carbonmonoxy-myoglobin UV-vis assay for reliable determination of CO-release rates from organometallic carbonyl complexes. Dalton Trans 2011;40:5755-5761.

[40] McLean S, Mann BE, Poole RK. Sulfite species enhance carbon monoxide release from CO-releasing molecules: implications for the deoxymyoglobin assay of activity. Anal Biochem 2012;427:36-40.

[41] Motterlini R, Sawle P, Bains S, Hammad J, Alberto R, Foresti R, Green CJ. CORM-A1: a new pharmacologically active carbon monoxide-releasing molecule. FASEB J 2005; 19:284-286.

[42] Desmard M, Davidge KS, Bouvet O, Morin D, Roux D, Foresti R, Ricard JD, Denamur E, Poole RK, Montravers P, Motterlini R, Boczkowski J. A carbon monoxide-releasing molecule (CORM-3) exerts bactericidal activity against Pseudomonas aeruginosa and improves survival in an animal model of bacteraemia. FASEB J 2009;23:1023-1031. 
[43] Clark JE, Foresti R, Green CJ, Motterlini R. Dynamics of haem oxygenase-1 expression and bilirubin production in cellular protection against oxidative stress. Biochem $\mathrm{J}$ 2000;348:615-619.

[44] Garrido-Mesa N, Camuesco D, Arribas B, Comalada M, Bailon E, Cueto-Sola M, Utrilla P, Nieto A, Zarzuelo A, Rodriguez-Cabezas ME, Galvez J. The intestinal antiinflammatory effect of minocycline in experimental colitis involves both its immunomodulatory and antimicrobial properties. Pharmacol Res 2011;63:308-319.

[45] Foresti R, Hammad J, Clark JE, Johnson RA, Mann BE, Friebe A, Green CJ, Motterlini R. Vasoactive properties of CORM-3, a novel water-soluble carbon monoxide-releasing molecule. Br J Pharmacol 2004;142:453-460.

[46] Khanna V, Jain M, Barthwal MK, Kalita D, Boruah JJ, Das SP, Islam NS, Ramasarma T, Dikshit M. Vasomodulatory effect of novel peroxovanadate compounds on rat aorta: Role of rho kinase and nitric oxide/cGMP pathway. Pharmacol Res 2011;64:274-282.

[47] Motterlini R. Carbon monoxide-releasing molecules (CO-RMs): vasodilatory, antiischemic and anti-inflammatory activities. Biochem Soc Trans 2007;35:1142-1146.

[48] Foresti $\mathrm{R}$ and Motterlini R. Interaction of carbon monoxide with transition metals: evolutionary insights into drug target discovery. Curr Drug Targets 2010;11:1595-1604.

[49] Sandouka A, Fuller BJ, Mann BE, Green CJ, Foresti R, Motterlini R. Treatment with carbon monoxide-releasing molecules (CO-RMs) during cold storage improves renal function at reperfusion. Kidney Int 2006;69:239-247.

[50] Tayem Y, Johnson TR, Mann BE, Green CJ, Motterlini R. Protection against cisplatininduced nephrotoxicity by a carbon monoxide-releasing molecule. Am J Physiol Renal Physiol 2006;290:F789-F794.

[51] Gonzalez MA, Yim MA, Cheng S, Moyes A, Hobbs AJ, Mascharak PK. Manganese carbonyls bearing tripodal polypyridine ligands as photoactive carbon monoxide-releasing molecules. Inorg Chem 2012;51:601-608. 
[52] Bikiel DE, Gonzalez SE, Di Salvo F, Milagre HM, Eberlin MN, Correa RS, Ellena J, Estrin DA, Doctorovich F. Tetrachlorocarbonyliridates: Water-Soluble Carbon Monoxide Releasing Molecules Rate-Modulated by the Sixth Ligand. Inorg Chem 2011;50:23342345.

[53] Zhang WQ, Atkin AJ, Thatcher RJ, Whitwood AC, Fairlamb IJ, Lynam JM. Diversity and design of metal-based carbon monoxide-releasing molecules (CO-RMs) in aqueous systems: revealing the essential trends. Dalton Trans 2009;4351-4358.

[54] Decaluwe K, Pauwels B, Verpoest S, Van de Voorde J. Divergent mechanisms involved in CO and CORM-2 induced vasorelaxation. Eur J Pharmacol 2012;674:370-377.

[55] Desmard M, Foresti R, Morin D, Dagoussat M, Berdeaux A, Denamur E, Crook SH, Mann BE, Scapens D, Montravers P, Boczkowski J, Motterlini R. Differential Antibacterial Activity Against Pseudomonas aeruginosa by Carbon Monoxide-Releasing Molecules. Antioxid Redox Signal 2011;16:153-163.

[56] Stohs SJ and Bagchi D. Oxidative mechanisms in the toxicity of metal ions. Free Radic Biol Med 1995;18:321-336.

[57] Tavares AF, Teixeira M, Romao CC, Seixas JD, Nobre LS, Saraiva LM. Reactive oxygen species mediate bactericidal killing elicited by carbon monoxide-releasing molecules. J Biol Chem 2011;286:26708-26717.

[58] Murray TS, Okegbe C, Gao Y, Kazmierczak BI, Motterlini R, Dietrich LE, Bruscia EM. The carbon monoxide releasing molecule CORM-2 attenuates Pseudomonas aeruginosa biofilm formation. PLoS One 2012;7:e35499.

[59] Jackson CS, Schmitt S, Dou QP, Kodanko JJ. Synthesis, Characterization, and Reactivity of the Stable Iron Carbonyl Complex $[\mathrm{Fe}(\mathrm{CO})(\mathrm{N} 4 \mathrm{Py})](\mathrm{ClO}(4))(2)$ : Photoactivated Carbon Monoxide Release, Growth Inhibitory Activity, and Peptide Ligation. Inorg Chem 2011;50:5336-5338. 


\section{Figure Legends}

Figure 1 Chemical structure of iron-containing CO-RMs and quantification of CO release. (A) CORM-307, CORM-308 and CORM-314 are iron tricarbonyl complexes containing different halides (I, Br and $\mathrm{Cl}$, respectively) and are soluble in DMSO, whereas CORM-319 is an iron tetracarbonyl complex which is soluble in water. (B) CO-RMs $(10,20$ and $40 \mu \mathrm{M})$ were added to a solution containing deoxy-myoglobin and the formation of carbonmonoxy myoglobin (MbCO) was determined over time. The reported values are the maximal $\mathrm{MbCO}$ reached for each $\mathrm{CO}-\mathrm{RM}$ (see Materials and Methods). Bars represent the mean \pm S.E.M. of experiments performed in duplicate.

Figure 2. Biochemical and pharmacological properties of CORM-307. (A) Absorption spectra of carbonmonoxy myoglobin (MbCO, open symbols) formed over time after addition of CORM-307 $(40 \mu \mathrm{M})$ to a phosphate buffer solution containing deoxy-myoglobin (filled squares) (see Materials and Methods). Note: the Mb becomes fully saturated with $\mathrm{CO}$ within 5 min (see Soret peak at $540 \mathrm{~nm}$ ) and all the spectra recorded at subsequent times overlap the initial spectrum. (B) Quantification of MbCO formed over time after reaction of deoxy-Mb with $40 \mu \mathrm{M}$ CORM-307 or its inactive counterpart (iCORM-307). (C) Vasorelaxing effects of CORM-307. Precontracted rat aortic rings were exposed to a bolus addition of $100 \mu \mathrm{M}$ CORM-307 or iCORM307 and changes in tension were recorded over time. Data represent the mean \pm S.E.M. of 5 independent experiments and are expressed as a percentage of the initial contraction to phenylephrine. (D) Cytotoxicity profile of CORM-307. Cell viability was assessed $24 \mathrm{hr}$ after exposure of rat smooth muscle cells to CORM-307 or iCORM-307 (10-100 $\mu \mathrm{M})$ using the Alamar Blue assay (see Materials and Methods). Results represent the mean \pm S.E.M. of 5 
independent experiments. Bars are not visible when the cell viability is $0 \%$. $*$ indicates $\mathrm{P}<0.05$ vs. control $(0 \mu \mathrm{M})$.

Figure 3. Biochemical and pharmacological properties of CORM-308. (A) Absorption spectra of carbonmonoxy myoglobin (MbCO, open symbols) formed over time after addition of CORM-308 $(40 \mu \mathrm{M})$ to a phosphate buffer solution containing deoxy-myoglobin (filled squares) (see Materials and Methods). Note: the Mb becomes fully saturated with $\mathrm{CO}$ within 5 min (see Soret peak at $540 \mathrm{~nm}$ ) and all the spectra recorded at subsequent times overlap the initial spectrum. (B) Quantification of MbCO formed over time after reaction of deoxy-Mb with $40 \mu \mathrm{M}$ CORM-308 or its inactive counterpart (iCORM-308). (C) Vasorelaxing effects of CORM-308. Precontracted rat aortic rings were exposed to a bolus addition of $100 \mu \mathrm{M}$ CORM-308 or iCORM308 and changes in tension were recorded over time. Data represent the mean \pm S.E.M. of 5 independent experiments and are expressed as a percentage of the initial contraction to phenylephrine. (D) Cytotoxicity profile of CORM-308. Cell viability was assessed $24 \mathrm{hr}$ after exposure of rat smooth muscle cells to CORM-308 or iCORM-308 (10-100 $\mu \mathrm{M})$ using the Alamar Blue assay (see Materials and Methods). Results represent the mean \pm S.E.M. of 5 independent experiments. * indicates $\mathrm{P}<0.05$ vs. control $(0 \mu \mathrm{M})$.

Figure 4. Biochemical and pharmacological properties of CORM-314. (A) Absorption spectra of carbonmonoxy myoglobin (MbCO, open symbols) formed over time after addition of CORM-314 $(40 \mu \mathrm{M})$ to a phosphate buffer solution containing deoxy-myoglobin (filled squares) (see Materials and Methods). Note: the Mb becomes fully saturated with CO within 5 min (see Soret peak at $540 \mathrm{~nm}$ ) and all the spectra recorded at subsequent times overlap the initial spectrum. (B) 
Quantification of MbCO formed over time after reaction of deoxy-Mb with $40 \mu \mathrm{M}$ CORM-314 or its inactive counterpart (iCORM-314). (C) Vasorelaxing effects of CORM-314. Precontracted rat aortic rings were exposed to a bolus addition of $100 \mu \mathrm{M}$ CORM-314 or iCORM314 and changes in tension were recorded over time. Data represent the mean \pm S.E.M. of 5 independent experiments and are expressed as a percentage of the initial contraction to phenylephrine. (D) Cytotoxicity profile of CORM-314. Cell viability was assessed $24 \mathrm{hr}$ after exposure of rat smooth muscle cells to CORM-314 or iCORM-314 $(10-100 \mu \mathrm{M})$ using the Alamar Blue assay (see Materials and Methods). Results represent the mean \pm S.E.M. of 5 independent experiments. Bars are not visible when the cell viability is $0 \%$. * indicates $\mathrm{P}<0.05$ vs. control $(0 \mu \mathrm{M})$.

Figure 5. Biochemical and pharmacological properties of CORM-319. (A) Absorption spectra of carbonmonoxy myoglobin (MbCO, open symbols) formed over time after addition of CORM-319 $(40 \mu \mathrm{M})$ to a phosphate buffer solution containing deoxy-myoglobin (filled squares) (see Materials and Methods). (B) Quantification of MbCO formed over time after reaction of deoxy$\mathrm{Mb}$ with $40 \mu \mathrm{M}$ CORM-319 or its inactive counterpart (iCORM-319). Inset: Detection of CO release from CORM319 using an amperometric CO electrode. Changes in current over time is reported after addition of $100 \mu \mathrm{M}$ CORM-319 to a phosphate buffer solution $(\mathrm{pH}=7.4)(\mathbf{C})$ Vasorelaxing effects of CORM-319. Pre-contracted rat aortic rings were exposed to a bolus addition of $100 \mu \mathrm{M}$ CORM-319 or iCORM-319 and changes in tension were recorded over time. Data represent the mean \pm S.E.M. of 5 independent experiments and are expressed as a percentage of the initial contraction to phenylephrine. (D) Cytotoxicity profile of CORM-319. Cell viability was assessed $24 \mathrm{hr}$ after exposure of rat smooth muscle cells to CORM-319 or iCORM-319 (10- 
$100 \mu \mathrm{M}$ ) using the Alamar Blue assay (see Materials and Methods). Results represent the mean \pm S.E.M. of 5 independent experiments. * indicates $\mathrm{P}<0.05$ vs. control $(0 \mu \mathrm{M})$.

Figure 6. Effect of iron-containing CO-RMs on cell viability in RAW264.7 macrophages. Cell viability was assessed in macrophages $24 \mathrm{hr}$ after exposure to increasing concentrations of CORM-307 (A), CORM-308 (B), CORM-314 (C) or CORM-319 (C). Viability was expressed as percentage of control and the reported $\mathrm{IC}_{50}$ for each active CO-RM was expressed as the concentration necessary to cause $50 \%$ of cell damage. Data represent the mean \pm S.E.M. of 6 independent experiments. Bars are not visible when the cell viability is $0 \%$. * indicates $\mathrm{P}<0.05$ compared to controls $(0 \mu \mathrm{M}) ; \uparrow$ indicates $\mathrm{P}<0.05$ compared to inactive CO-RMs.

Figure 7. Effect of CO-RM-319 on LPS-stimulated nitrite production in RAW264.7 macrophages. Cells were exposed to $1 \mu \mathrm{g} / \mathrm{ml}$ LPS in the presence of increasing concentrations of CORM-319 (10-100 $\mu \mathrm{M})$ or its inactive counterpart (iCORM-319). Nitrite levels, an index of NO production, was assessed after $24 \mathrm{~h}$ exposure. Control cells were incubated with medium alone (open bars). Data represent the mean \pm S.E.M. of 6 independent experiments. * indicates $\mathrm{P}$ $<0.05$ compared to LPS-treated cells. 
Figure 1

A
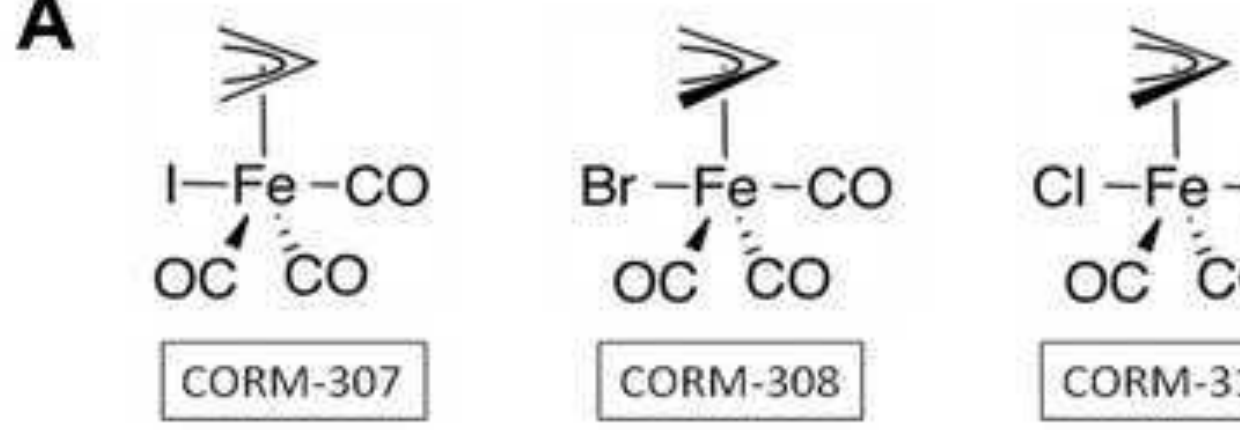<smiles>O=[Fe][Ba]Br</smiles>
OC $\mathrm{CO}$ $\mathrm{Cl}-\mathrm{Fe}-\mathrm{CO}$

CORM-308

CORM-314

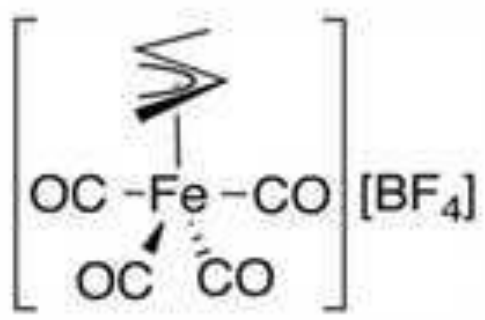

\section{CORM-319}

B

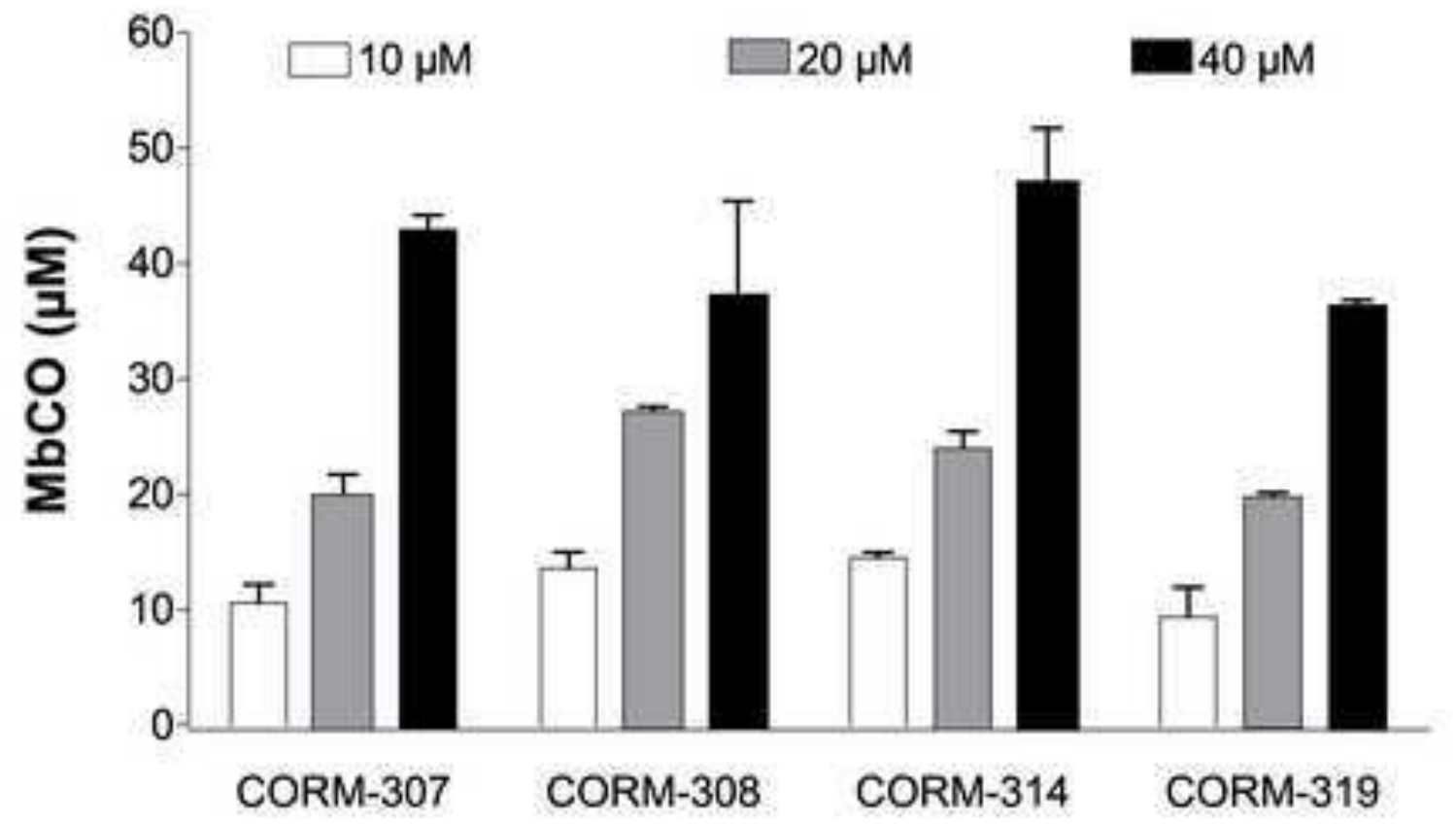


A

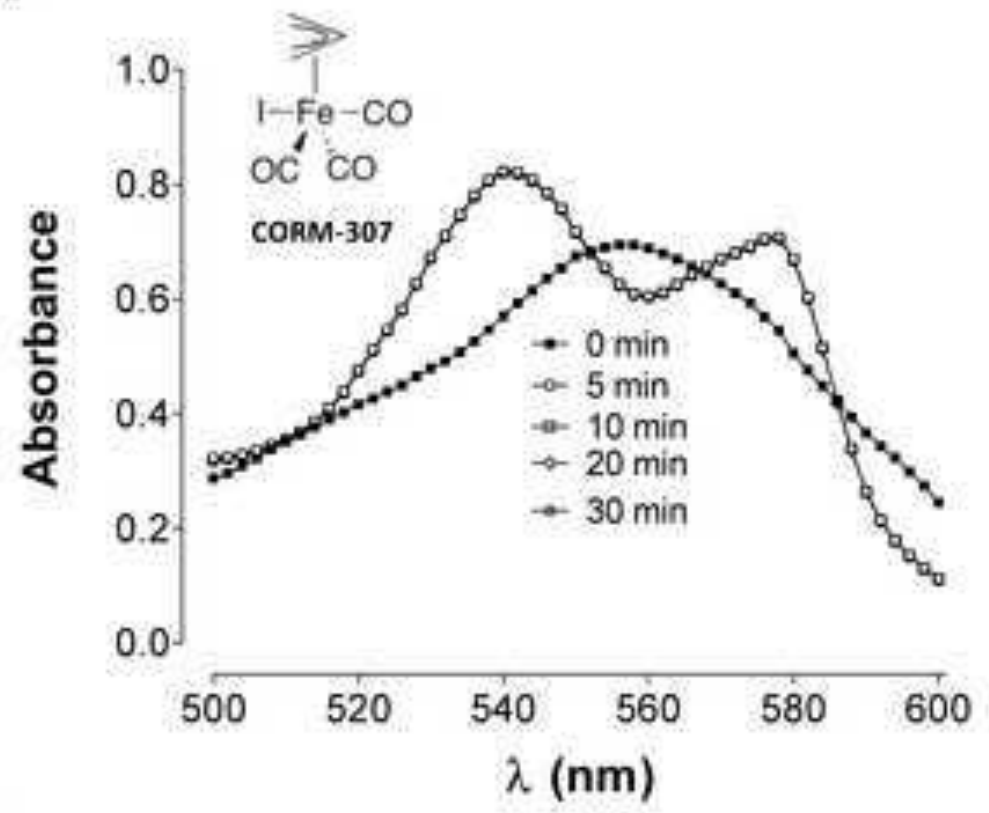

C

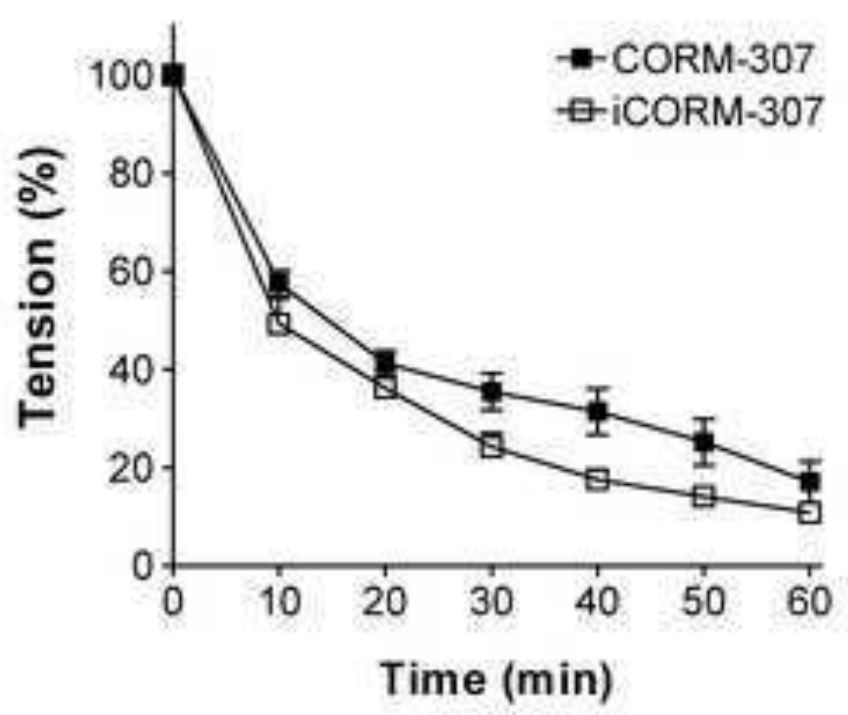

B

Figure 2

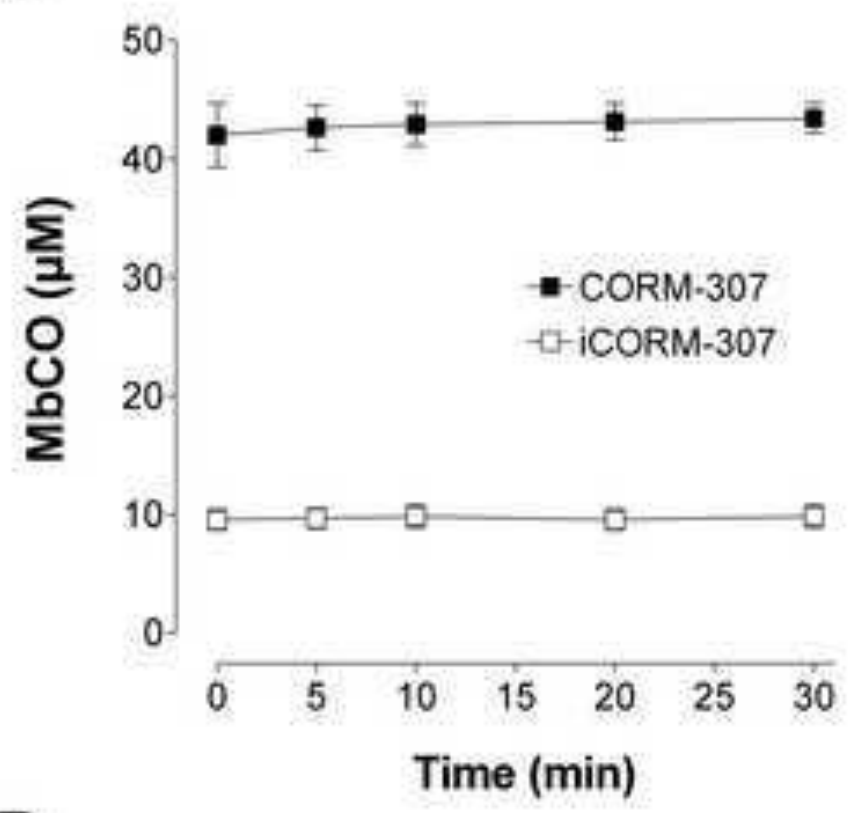

D

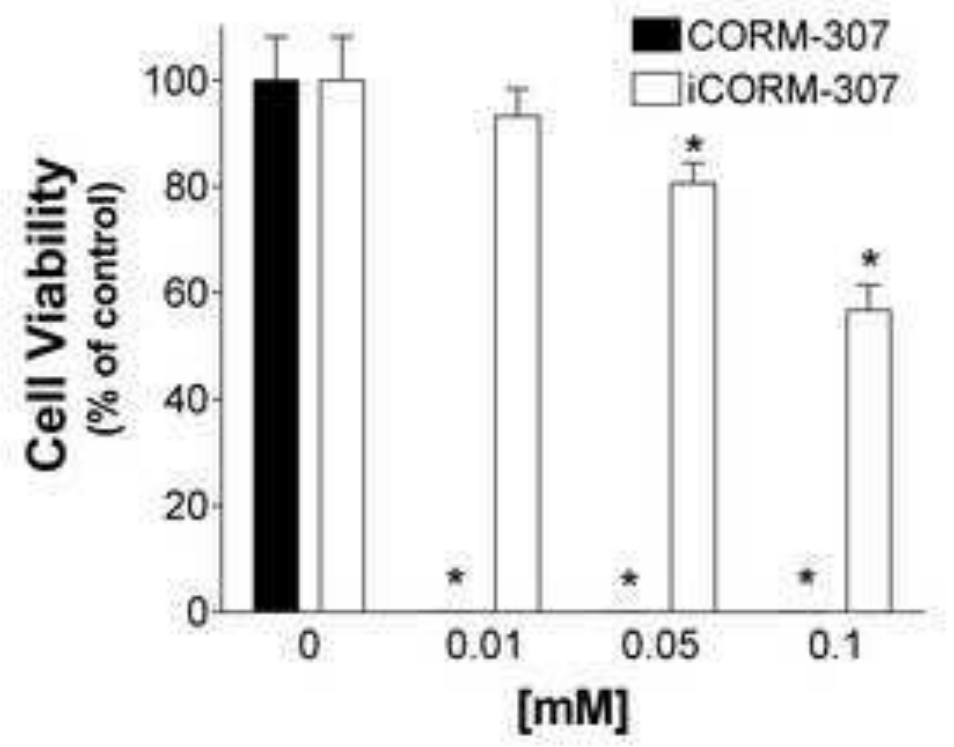

rage 34 ot 40 
A

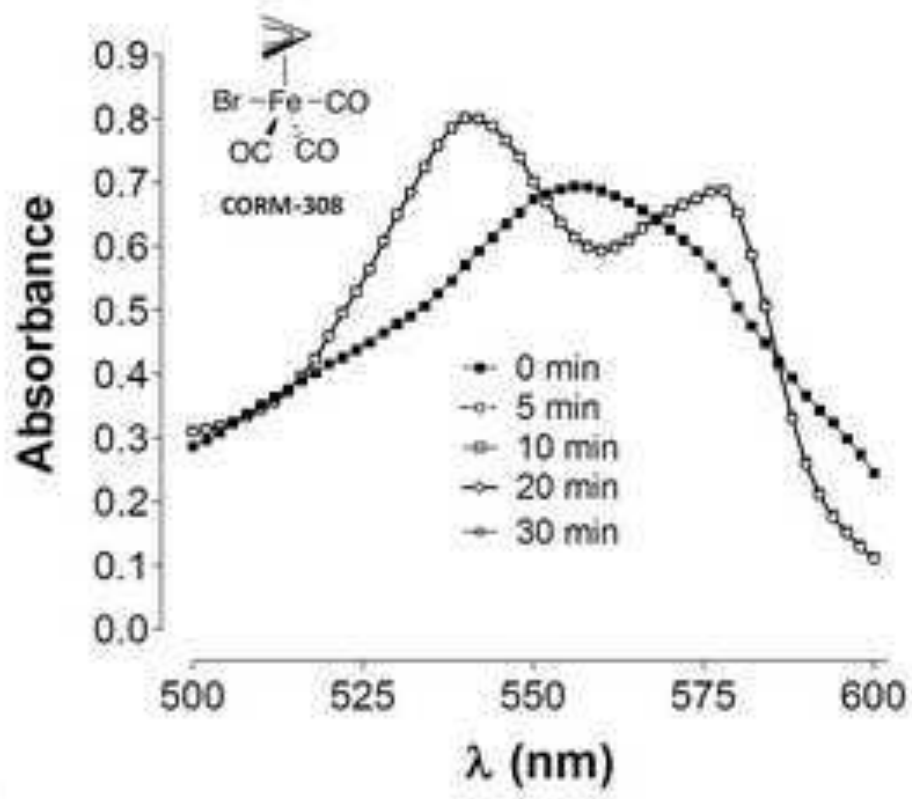

C

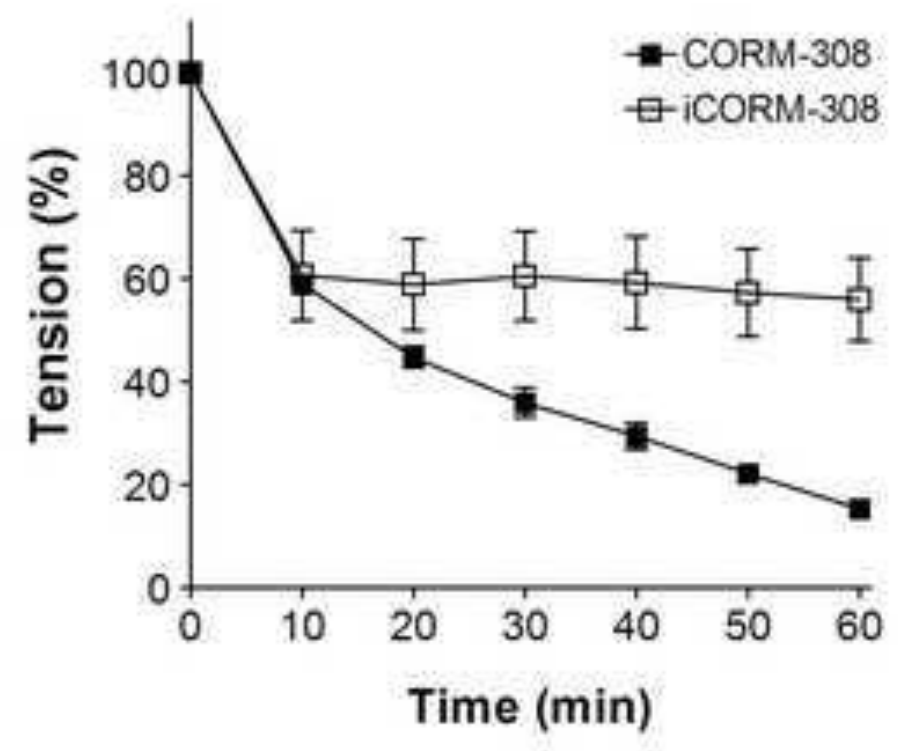

B

Figure 3

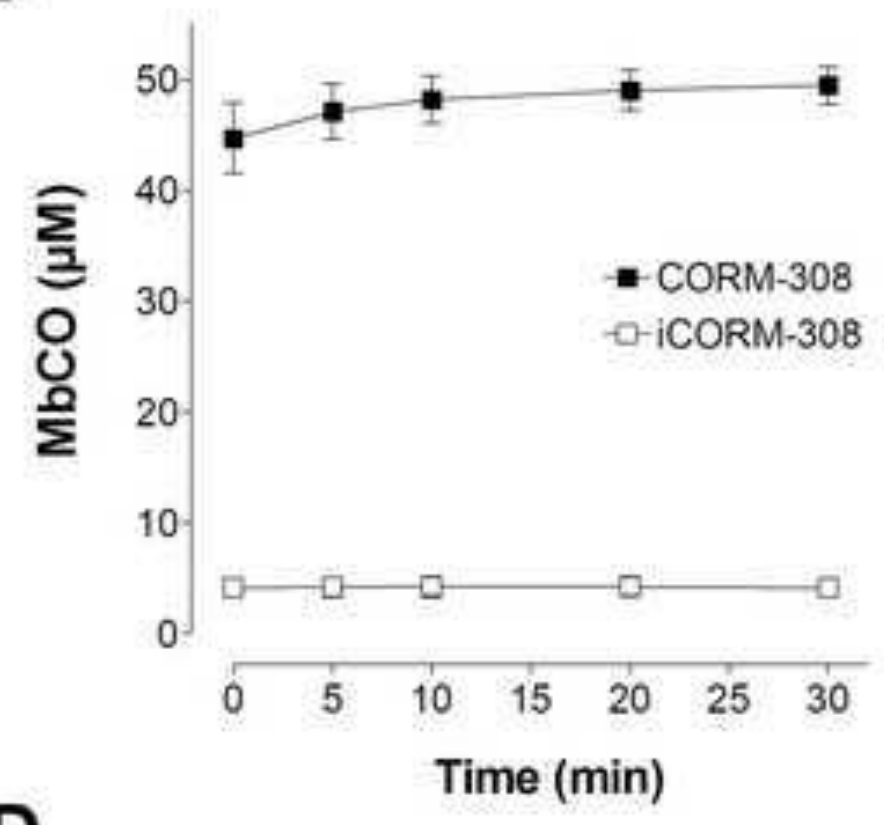

D

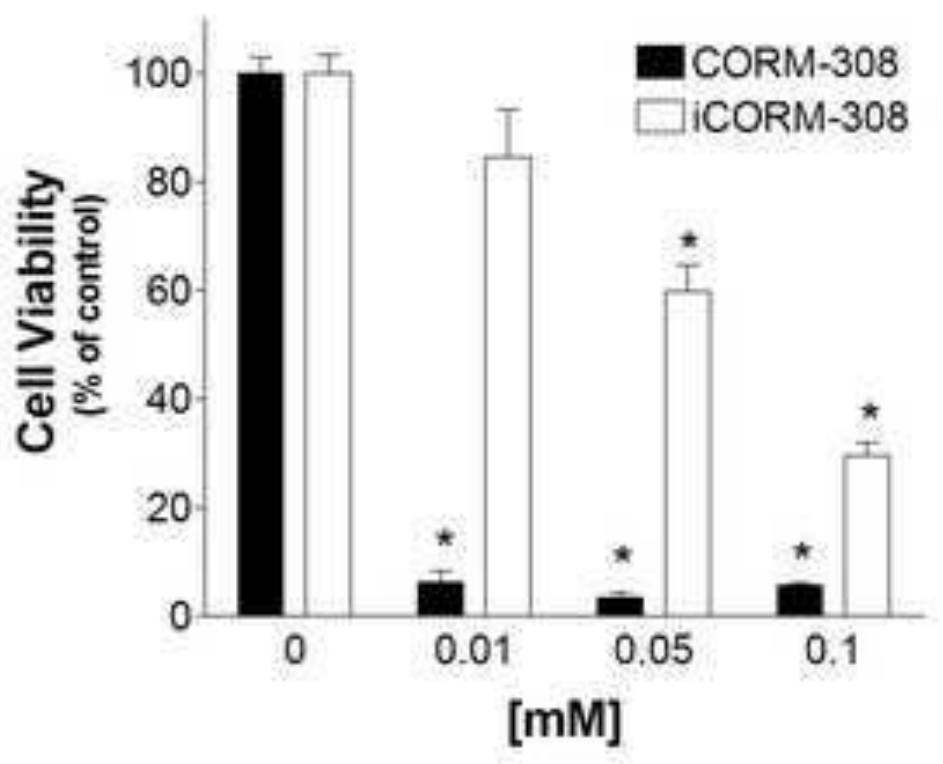

rage 35 or 40 
A

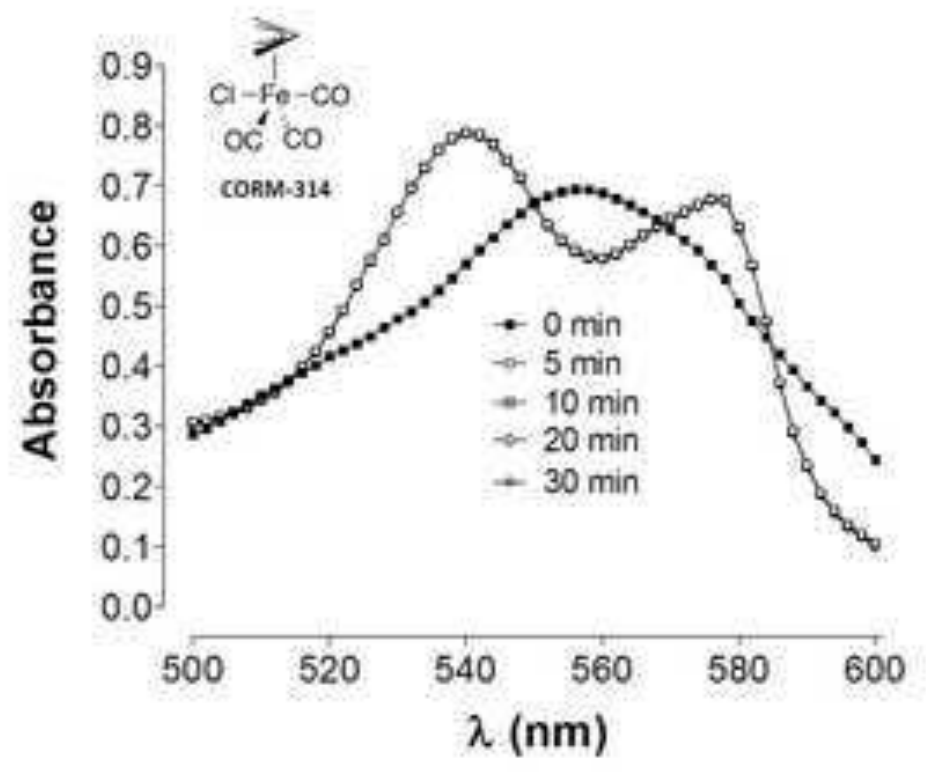

C

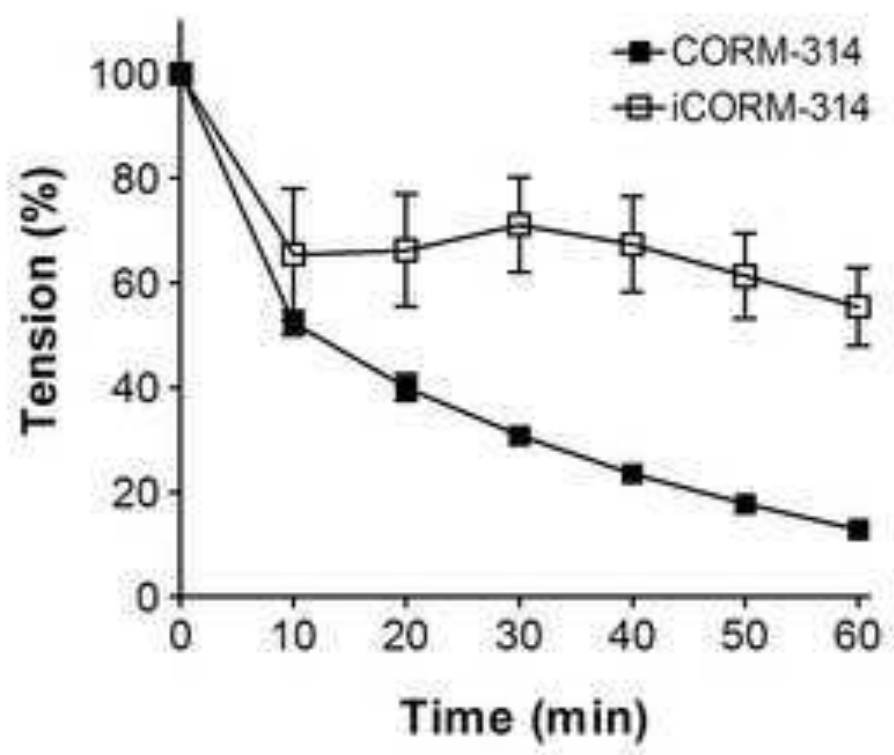

B

Figure 4

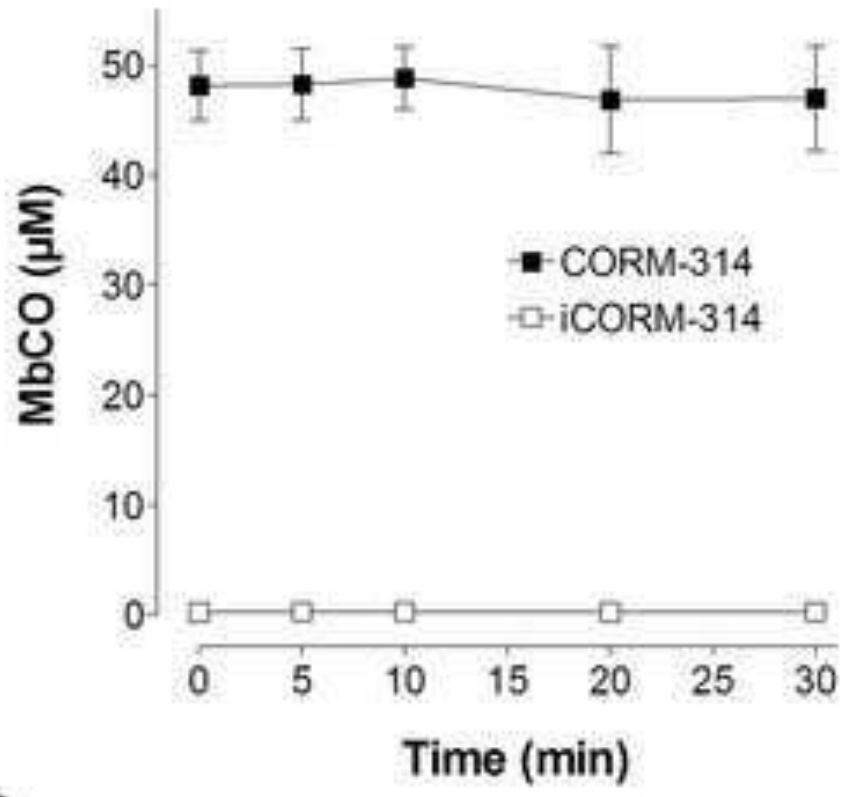

D

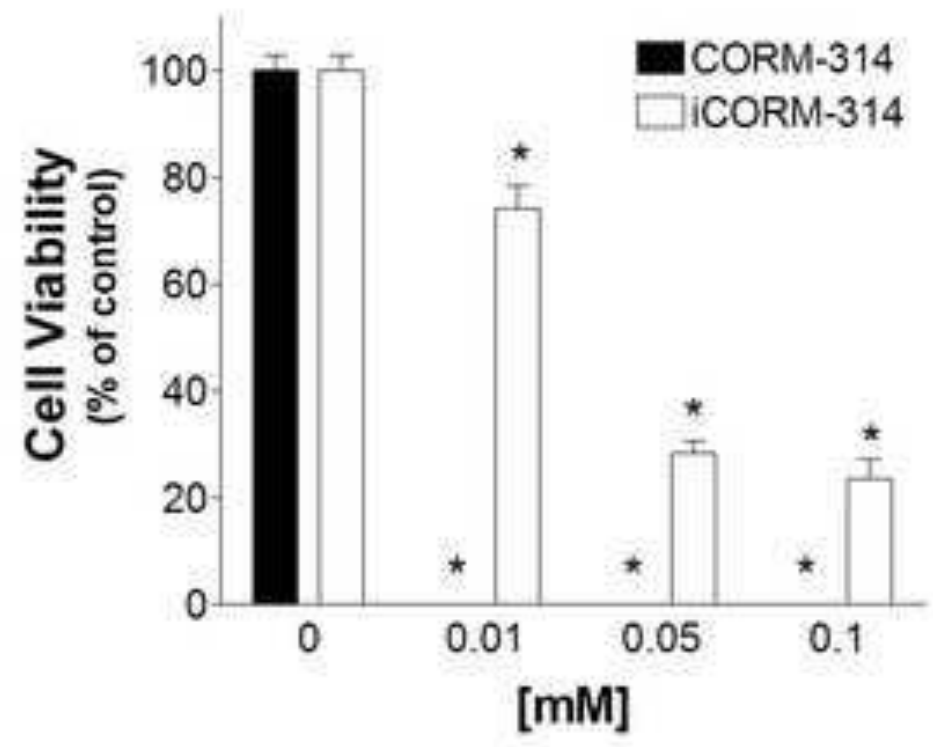

rage 36 or 40 
A

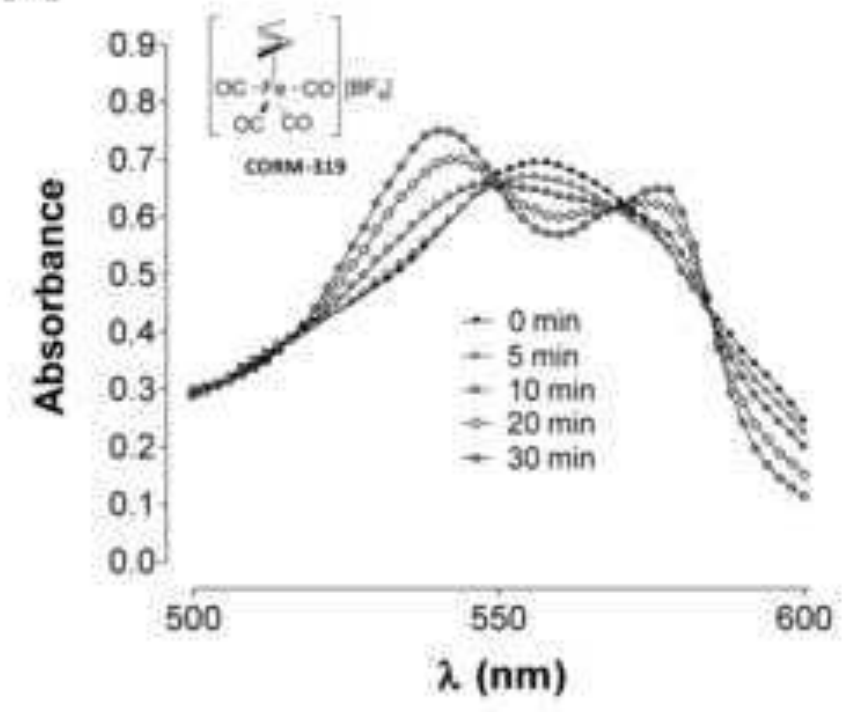

C

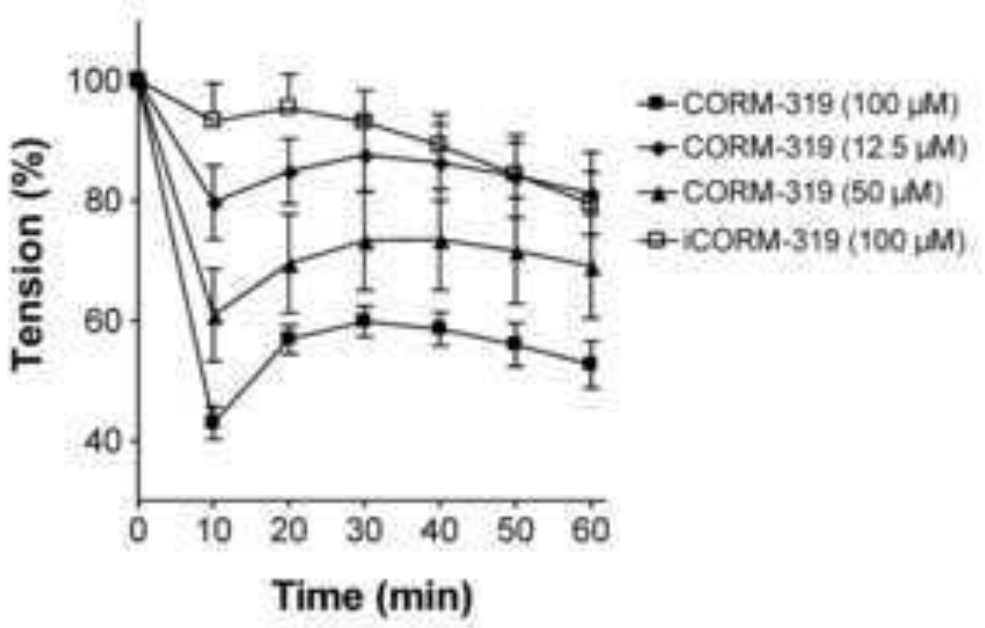

Figure 5

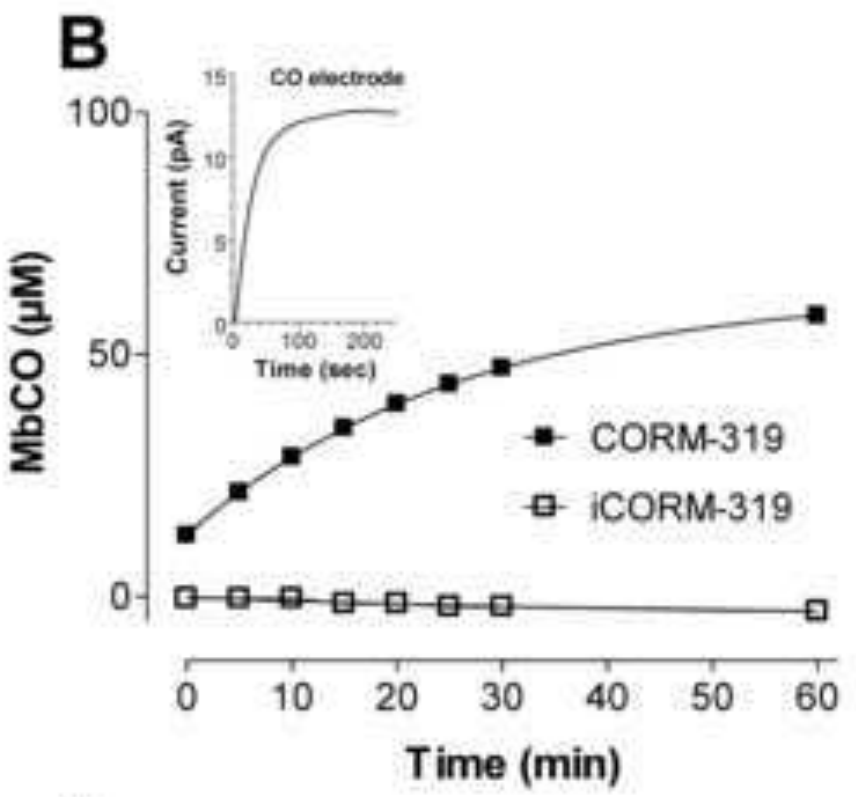

D

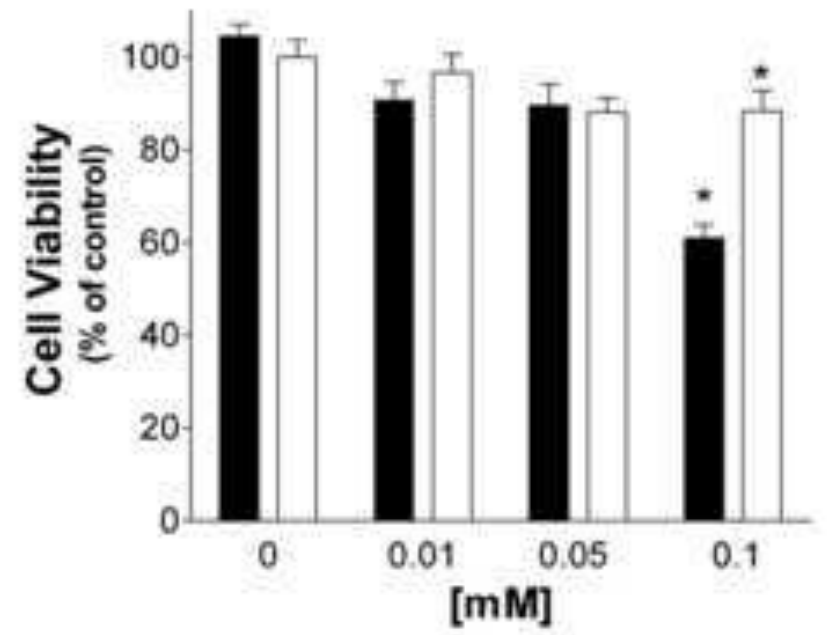

- CORM-319 $\square$ ICORM-319 
A

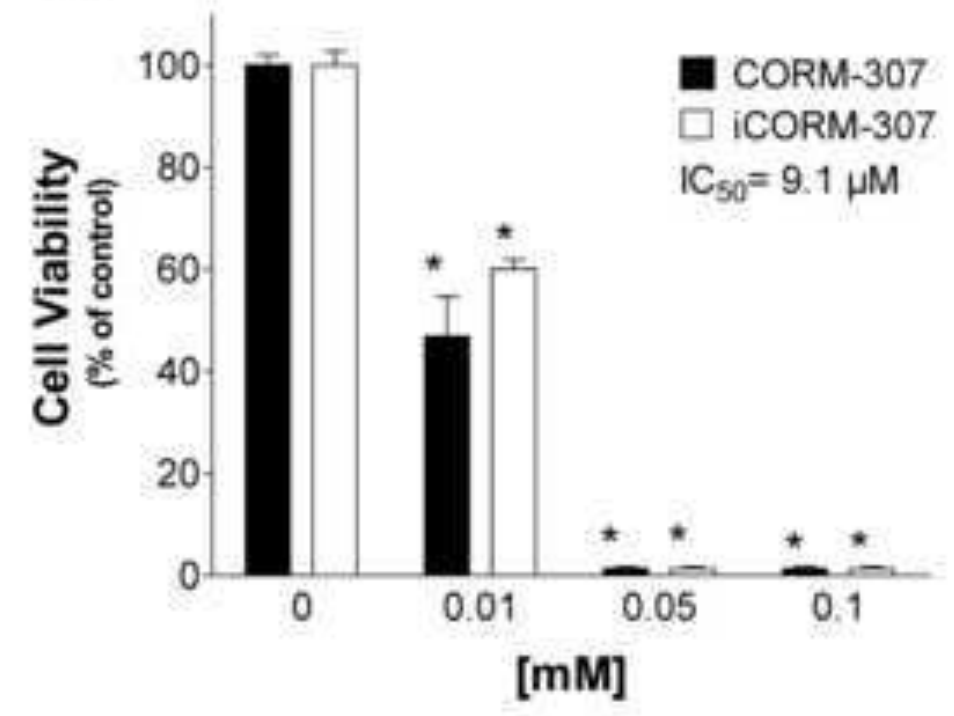

C

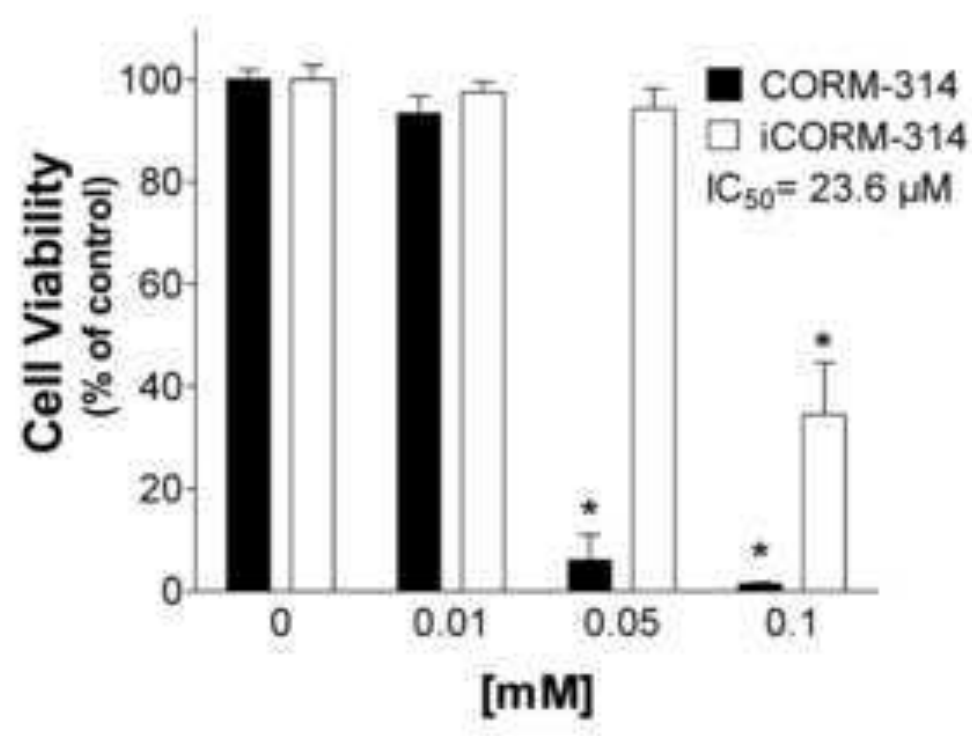

B

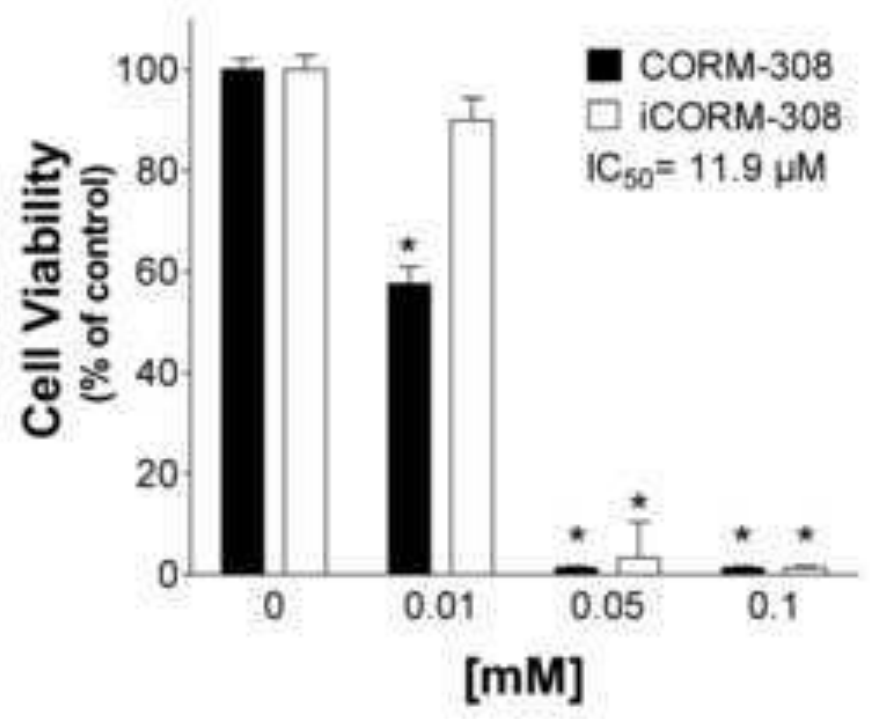

D

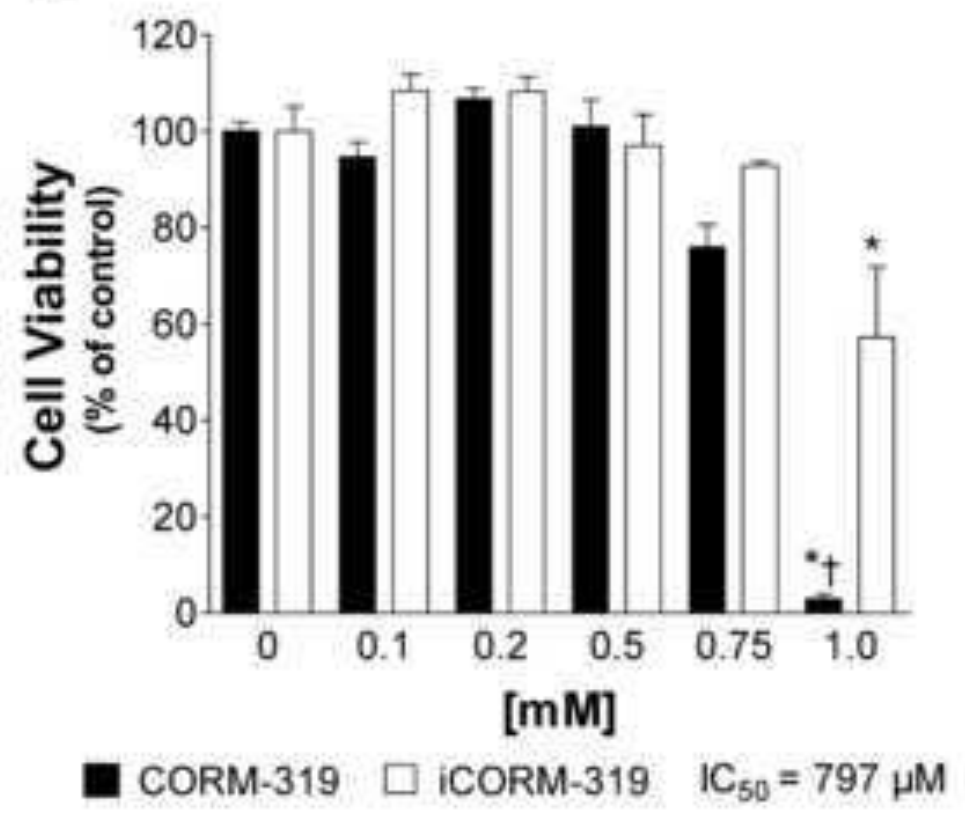


Figure 7

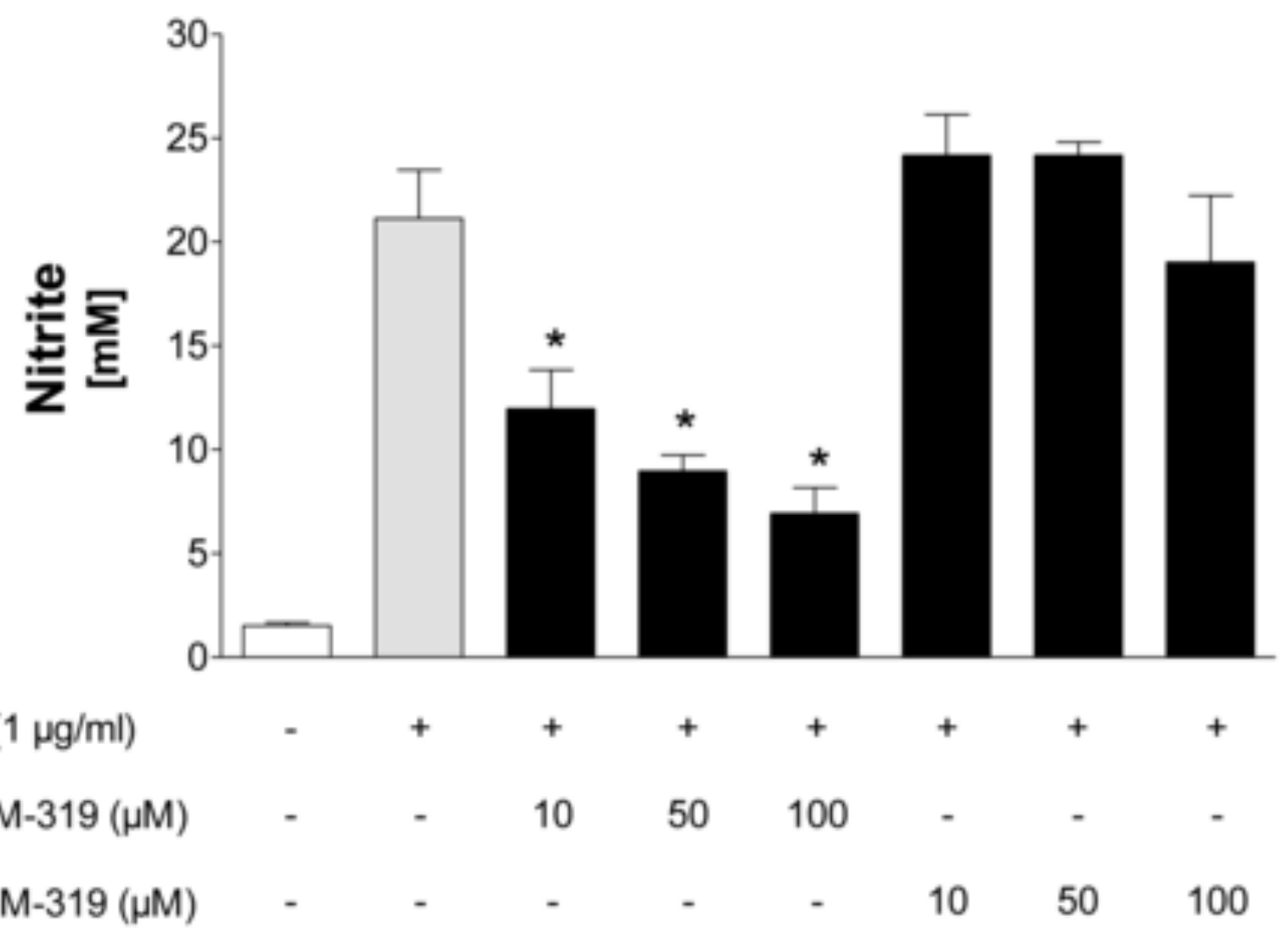




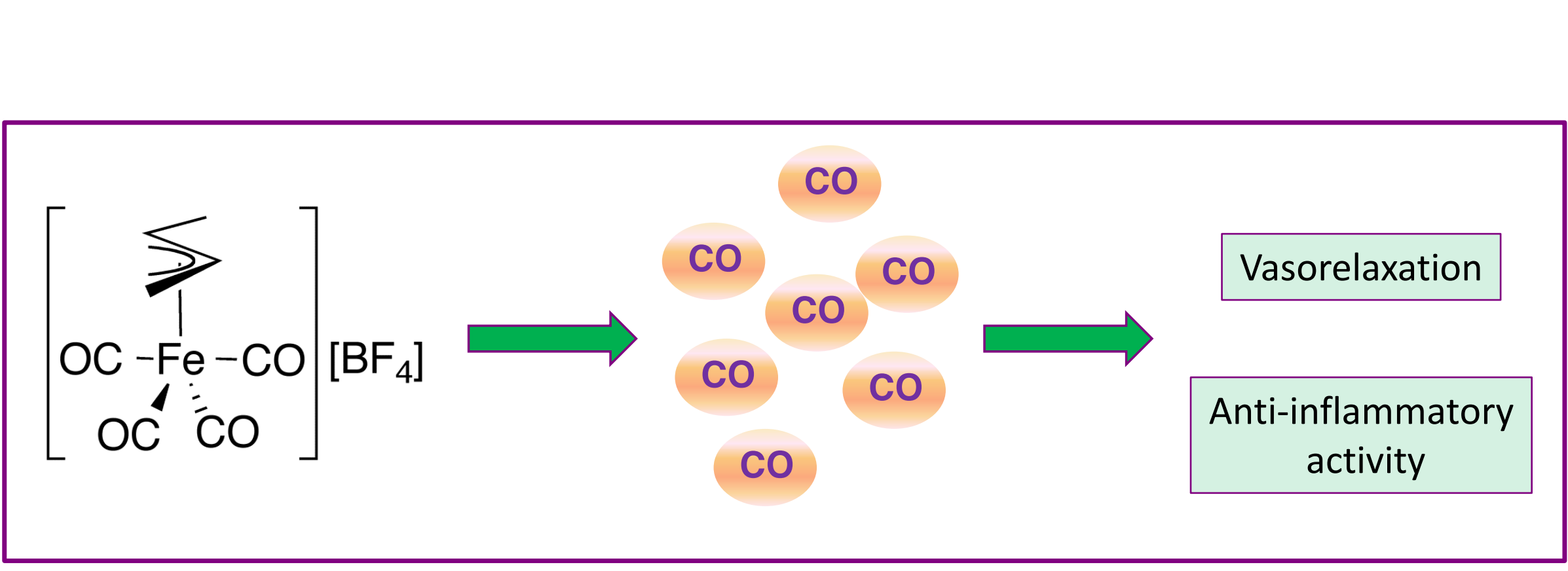

